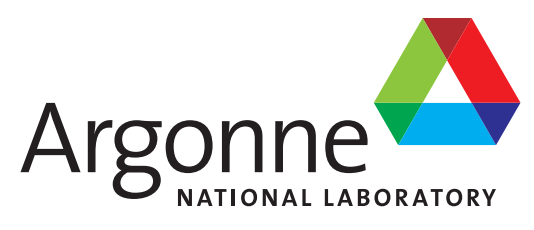

ANL-11/06

\title{
Hydrogen Separation Membranes
}

Annual Report for FY 2010

\author{
Energy Systems Division
}




\begin{abstract}
About Argonne National Laboratory
Argonne is a U.S. Department of Energy laboratory managed by UChicago Argonne, LLC under contract DE-AC02-06CH11357. The Laboratory's main facility is outside Chicago, at 9700 South Cass Avenue, Argonne, Illinois 60439. For information about Argonne and its pioneering science and technology programs, see www.anl.gov.
\end{abstract}

\title{
Availability of This Report
}

This report is available, at no cost, at http://www.osti.gov/bridge. It is also available on paper to the U.S. Department of Energy and its contractors, for a processing fee, from:

U.S. Department of Energy

Office of Scientific and Technical Information

P.O. Box 62

Oak Ridge, TN 37831-0062

phone (865) 576-8401

fax (865) 576-5728

reports@adonis.osti.gov

\begin{abstract}
Disclaimer
This report was prepared as an account of work sponsored by an agency of the United States Government. Neither the United States Government nor any agency thereof, nor UChicago Argonne, LLC, nor any of their employees or officers, makes any warranty, express or implied, or assumes any legal liability or responsibility for the accuracy, completeness, or usefulness of any information, apparatus, product, or process disclosed, or represents that its use would not infringe privately owned rights. Reference herein to any specific commercial product, process, or service by trade name, trademark, manufacturer, or otherwise, does not necessarily constitute or imply its endorsement, recommendation, or favoring by the United States Government or any agency thereof. The views and opinions of document authors expressed herein do not necessarily state or reflect those of the United States Government or any agency thereof, Argonne National Laboratory, or UChicago Argonne, LLC.
\end{abstract}




\section{Hydrogen Separation Membranes}

Annual Report for FY 2010

by

U. (Balu) Balachandran, S.E. Dorris, J.E. Emerson,

T.H. Lee, Y. Lu, C.Y. Park, and J.J. Picciolo

Energy Systems Division, Argonne National Laboratory

January 30, 2011 


\section{Contents}

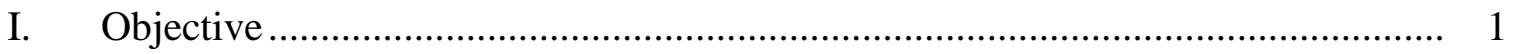

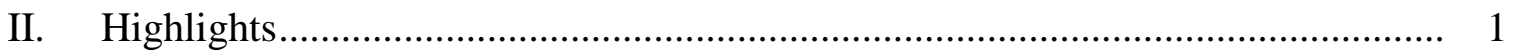

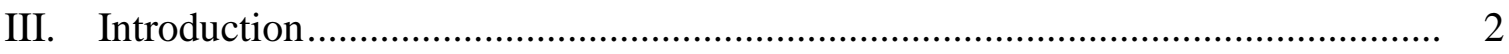

IV. Results............................................................................................... 3

Milestone 1. Measure hydrogen flux of HTM made from non-precious metal... 3

Milestone 2. Test tubular thin-film membrane under all test conditions prescribed by the NETL test protocol...................................... 7

Milestone 3. Correlate flux and phase boundary data at low temperatures......................................................................... 11

Additional. Monitor hydrogen flux for thin-film ANL-3e membrane during exposure for $\approx 4$ months to simulated "coal gas”................ 16

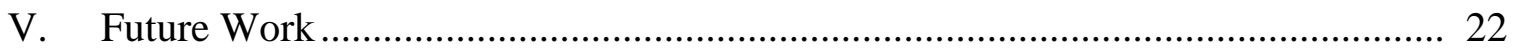

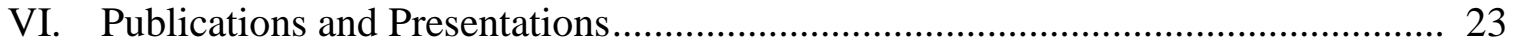

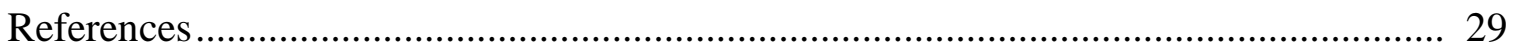




\section{Figures}

1. Hydrogen flux for commercial $\mathrm{Nb}$ foils

2. Hydrogen flux of commercial 0.25-mm-thick $\mathrm{Nb}$ foil measured with $\mathrm{Ar}$ as sweep gas and $3.5 \% \mathrm{H}_{2} /$ balance He as feed gas

3. Hydrogen flux at $354^{\circ} \mathrm{C}$ of 0.25 -mm-thick commercial Ta foil vs. time of exposure to $80 \% \mathrm{H}_{2}$ /balance He as feed and UHP Ar as sweep ............................... 5

4. Hydrogen flux of commercial Ta foil at 304 and $354^{\circ} \mathrm{C}$ vs. $\Delta \mathrm{pH}_{2}{ }^{1 / 2}$....................... 6

5. Hydrogen flux of commercial Ta foil vs. temperature with $80 \% \mathrm{H}_{2}$ /balance He as feed gas and UHP Ar as sweep gas

6. Hydrogen flux measured at Argonne using tubular Pd-Au alloy membrane from Pall Corp. vs. time during four tests in HTM test protocol.

7. Hydrogen purity measured at Argonne using tubular Pd-Au alloy membrane from Pall Corp. vs. time during four tests in HTM test protocol

8. Hydrogen purity measured at Argonne using tubular Pd-Au alloy membrane from Pall Corp. vs. time during first three of four tests in HTM test protocol........... 11

9. Hydrogen flux of Pd foil at $540^{\circ} \mathrm{C}$ in feed gas with $30 \% \mathrm{H}_{2} / \mathrm{He}$ and various $\mathrm{H}_{2} \mathrm{~S}$ concentrations.

10. Plan view of Pd foil before test in $30 \% \mathrm{H}_{2} /$ Hewith $5-44 \mathrm{ppm}_{2} \mathrm{~S}$ at $540^{\circ} \mathrm{C}$ and after test

11. Hydrogen flux of ANL-3e thin film at $540^{\circ} \mathrm{C}$ in feed gas with $20 \mathrm{ppm}_{2} \mathrm{~S}$ in $33 \% \mathrm{H}_{2} / \mathrm{He}, 33 \% \mathrm{H}_{2} / \mathrm{He}$ without $\mathrm{H}_{2} \mathrm{~S}$, and He without $\mathrm{H}_{2} \mathrm{~S}$.

12. Fracture surface of ANL-3e thin film after test at $540^{\circ} \mathrm{C}$ in feed gas of $33 \%$ $\mathrm{H}_{2}$ with various $\mathrm{H}_{2} \mathrm{~S}$ concentrations.

13. Hydrogen flux of ANL-3e thin film at $540^{\circ} \mathrm{C}$ in feed gas with 10 or $20 \mathrm{ppm}$ $\mathrm{H}_{2} \mathrm{~S}$ in $33 \% \mathrm{H}_{2} / \mathrm{He}$, He without $\mathrm{H}_{2} \mathrm{~S}$, and $33 \% \mathrm{H}_{2} /$ He without $\mathrm{H}_{2} \mathrm{~S}$

14. Hydrogen flux during long-term stability test of ANL-3e thin film at different temperatures in coal gas.

15. Hydrogen flux vs. time of ANL-3e thin film at different temperatures during long-term stability test in coal gas

16. Hydrogen flux measured with feed of $50 \% \mathrm{H}_{2} / \mathrm{He}$ before and after testing stability of ANL-3e thin film for $\approx 700 \mathrm{~h}$ at $500^{\circ} \mathrm{C}$ in coal gas. 
17. Leakage of $\mathrm{He}$ and $\mathrm{CO}_{2}$ at different temperatures during long-term stability test of ANL-3e thin film in coal gas..

18. $\mathrm{H}_{2} / \mathrm{CO}_{2}$ selectivity and $\mathrm{H}_{2} /$ He selectivity of ANL-3e thin film during longterm stability test of ANL-3e thin film at $400-600^{\circ} \mathrm{C}$.

\section{Tables}

1. Target and actual feed gas compositions during testing of tubular membrane from Pall Corp. according to HTM test protocol.

2. Compositions of $\mathrm{H}_{2} / \mathrm{CO} / \mathrm{CO}_{2}$ gases used to prepare feed gas mixtures for testing tubular membrane (Pall Corp.) according to HTM test protocol.....................

3. Flow rates of gases used to prepare feed gas mixtures for testing tubular membrane from Pall Corp. according to HTM test protocol. 


\section{HYDROGEN SEPARATION MEMBRANES -- ANNUAL REPORT FOR FY 2010 \\ ARGONNE NATIONAL LABORATORY}

Project Title: Development of Dense Ceramic Membranes for Hydrogen Separation

NETL Project Manager: Richard Dunst

ANL Project PI: U. (Balu) Balachandran

B\&R Code/Contract Number: AA-10-40-00-0/FWP 49601

Report Date: January 30, 2011

\section{OBJECTIVE}

The objective of this work is to develop dense ceramic membranes for separating hydrogen from other gaseous components in a nongalvanic mode, i.e., without using an external power supply or electrical circuitry.

\section{HIGHLIGHTS}

1. We achieved a milestone by measuring the hydrogen flux of membrane samples made from Pd-coated non-precious metals ( $\mathrm{Nb}$ and $\mathrm{Ta}$ foils) as a substitute for the expensive Pd presently used. With decreasing temperature, $\mathrm{H}_{2}$ percentage in the feed gas, and test time (up to 50 hours), the hydrogen flux decreased over time. The reason for this decrease is under investigation.

2. We achieved a second milestone by testing a tubular thin-film membrane under all test conditions prescribed by the NETL test protocol. The tubular membranes were fabricated by Pall Corp. The hydrogen flux was 6.4 to $10.8 \mathrm{~cm} / 3 \mathrm{~min}-\mathrm{cm}^{2}$ and remained stable over 150 hours in three of the four tests. Due to concentration polarization effects, the flux values are much lower than those obtained in tests performed by Pall Corp.

3. We achieved a third milestone by correlating the hydrogen flux and $\mathrm{Pd} / \mathrm{Pd}_{4} \mathrm{~S}$ phase boundary data at low temperatures $\left(500-600^{\circ} \mathrm{C}\right)$. At $540^{\circ} \mathrm{C}$, the phase boundary appeared at a slightly lower $\mathrm{H}_{2} \mathrm{~S}$ concentration for ANL-3e thin film (10-20 ppm) than Pd foil (30-32 ppm).

4. We also monitored the hydrogen flux of an ANL-3e thin film for $\approx 4$ months during exposure to simulated "coal gas" $\left(51 \% \mathrm{H}_{2} / 31 \% \mathrm{CO}_{2} / 1 \% \mathrm{CO} / 17 \% \mathrm{He}\right)$ at $400^{\circ} \mathrm{C}$ $600^{\circ} \mathrm{C}$. The effect of coal gas on the hydrogen flux depended strongly on temperature. The hydrogen flux decreased sharply in coal gas at $500^{\circ} \mathrm{C}$, but the decrease was reversed when coal gas was removed. At $600^{\circ} \mathrm{C}$, coal gas did not affect the hydrogen flux. 


\section{INTRODUCTION}

The goal of this project is to develop dense hydrogen transport membranes (HTMs) that nongalvanically (i.e., without electrodes or external power supply) separate hydrogen from gas mixtures at commercially significant fluxes under industrially relevant operating conditions. These membranes will be used to separate hydrogen from gas mixtures such as the product streams from coal gasification, methane partial oxidation, and water-gas shift reactions. Potential ancillary uses of HTMs include dehydrogenation and olefin production, as well as hydrogen recovery in petroleum refineries and ammonia synthesis plants, the largest current users of deliberately produced hydrogen. This report describes the results from the development and testing of HTM materials during FY 2010.

Materials development for the HTM follows a three-pronged approach at Argonne. In one approach, we utilize principles of solid-state defect chemistry to prepare selected electronic/protonic conductors (perovskites with substitutions on both A- and B-sites) that are chemically stable and have suitable protonic and electronic conductivities. The second approach uses cermet (i.e., ceramic/metal composite) membranes that are prepared by homogeneously mixing electronic/protonic conductors with a metal. The metal phase in cermets enhances the hydrogen permeability of the ceramic phase by increasing the electronic conductivity and by providing an additional transport path for the hydrogen, if the metal has high hydrogen permeability. In our third approach, we disperse a metal with high hydrogen permeability (i.e., a "hydrogen transport metal") in a ceramic or a metal matrix, with hydrogen being transported almost exclusively by the hydrogen transport metal. The matrix serves primarily as a chemically stable structural support in such composites. We focused during FY 2010 on further development of ANL-3e membranes (composed of Pd mixed with $\mathrm{Y}_{2} \mathrm{O}_{3}$-stabilized $\mathrm{ZrO}_{2}$ ), which have given the highest hydrogen flux for Argonne membranes $\left(\approx 26\right.$ and $\approx 50 \mathrm{~cm}^{3} / \mathrm{min}-\mathrm{cm}^{2}$ at 400 and $900^{\circ} \mathrm{C}$, respectively). Other membranes developed at Argonne are summarized elsewhere. [1]

According to the Department of Energy's 2015 targets for hydrogen separation membranes [2], the cost of HTMs must be $<\$ 100 / \mathrm{ft}^{2}$. Fabricating ANL-3e membranes with thickness of $2-5 \mu \mathrm{m}$ is one way to meet the cost target; another way is to fabricate HTMs with low-cost, non-precious hydrogen transport metals as a replacement for Pd. This report shows our latest results obtained with commercial $\mathrm{Nb}$ and Ta foils.

To allow comparison of various HTMs under uniform test conditions, a protocol for testing HTMs was established at a contractors' review meeting (April 29, 2008) in Morgantown, WV. A high-pressure permeation reactor at Argonne was modified for the purpose of testing HTMs according to the established protocol. The high-pressure reactor was used during FY 2010 to test a tubular thin-film membrane from Pall Corp. according to the established test protocol. This report presents the results from those tests.

Good chemical stability is a critical requirement for HTMs due to the corrosiveness of product streams from coal gasification and/or methane reforming. Hydrogen sulfide $\left(\mathrm{H}_{2} \mathrm{~S}\right)$ is a particularly corrosive contaminant that HTMs are expected to encounter. When $\mathrm{H}_{2} \mathrm{~S}$ reacts with palladium, palladium sulfide $\left(\mathrm{Pd}_{4} \mathrm{~S}\right)$ forms on the HTM's surface and 
impedes hydrogen permeation; therefore, the conditions for $\mathrm{Pd}_{4} \mathrm{~S}$-formation largely determine an ANL-3e membrane's tolerance for $\mathrm{H}_{2} \mathrm{~S}$. We determined the temperatures at which $\mathrm{Pd}_{4} \mathrm{~S}$ forms in specific feed gases containing 10-73\% $\mathrm{H}_{2}$ and $\approx 8-400 \mathrm{ppm}_{2} \mathrm{~S}$ [1] and located the $\mathrm{Pd} / \mathrm{Pd}_{4} \mathrm{~S}$ phase boundary at $500-600^{\circ} \mathrm{C}$ in feed gas with $10 \% \mathrm{H}_{2}$ [3, 4]. We correlated phase boundary data and hydrogen flux data for Pd foils and ANL-3e disks by measuring hydrogen flux while increasing the $\mathrm{H}_{2} \mathrm{~S}$ concentration in the feed gas. This report updates the correlation of low-temperature $\left(500-550^{\circ} \mathrm{C}\right)$ phase boundary data and hydrogen flux data. Because carbon monoxide (CO) is also reported [5-7] to adversely affect the performance of Pd-containing membranes, the variation in hydrogen flux for a thin-film ANL-3e membrane was studied during exposure for $\approx 4$ months to simulated “coal gas" ( $\left.51 \% \mathrm{H}_{2} / 31 \% \mathrm{CO}_{2} / 1 \% \mathrm{CO} / 17 \% \mathrm{He}\right)$ in the temperature range of $400^{\circ} \mathrm{C}-600^{\circ} \mathrm{C}$.

\section{RESULTS}

Results obtained during FY 2010 are presented below in relation to the pertinent milestone. Work that was done outside the scope of the milestones is also described.

\section{Milestone 1. Measure hydrogen flux of HTM made from non-precious metal.}

Non-precious metals are being tested as a substitute for Pd because Pd increases the cost of HTMs, and the hydrogen permeability of non-precious metals (e.g., Nb, V, Zr, and Ta) can be 10-100 times larger than that of Pd if their surface is properly treated. Figure 1 shows the time dependence of hydrogen flux for commercial $\mathrm{Nb}$ foils that were sputtercoated with $\mathrm{Pd}$ at room temperature. A thick $(1.0-\mathrm{mm})$ foil was tested during the early stages of this program at $420^{\circ} \mathrm{C}$ using $100 \% \mathrm{H}_{2}$ as the feed gas [8]. Tests were subsequently conducted under the same conditions except for $66 \%$ and $4 \% \mathrm{H}_{2}$ in the feed gas. More recently, flux for a thin $(0.25-\mathrm{mm}) \mathrm{Nb}$ disk was measured at $\approx 390-440^{\circ} \mathrm{C}$ in tests using $3.5 \% \mathrm{H}_{2}$ /balance $\mathrm{He}$ as the feed gas and either $\mathrm{N}_{2}$ or $\mathrm{Ar}$ as the sweep gas. Figure 1 shows results from measurements at $\approx 390^{\circ} \mathrm{C}$, which were made after the flux was measured first at $\approx 440^{\circ} \mathrm{C}$, then at $\approx 420^{\circ} \mathrm{C}$. Figure 2 shows the results from the flux measurements for the thin sample as a function of temperature.

As shown in Fig. 1, the flux for the thick foil with $100 \% \mathrm{H}_{2}$ feed gas was initially high, $12.6 \mathrm{~cm}^{3} / \mathrm{min}-\mathrm{cm}^{2}$, but decreased $\approx 20 \%$ in $27 \mathrm{~h}$. Another thick sample, not coated with Pd, gave no measurable hydrogen flux, indicating the importance of the Pd coating. As also evident in Fig. 1, the flux decreased with time for both thick and thin Nb samples and for all feed compositions. The decrease in flux might have occurred for several reasons. The Pd coating might "bead up" or crack on the surface of the disk, allowing the metal to react with oxygen (or nitrogen) in the feed, or the coating might be deactivated by interdiffusion with the underlying metal. Whether the sweep gas was $\operatorname{Ar}$ or $\mathrm{N}_{2}$, the flux appeared to decrease at about the same rate, suggesting that the decrease in flux did not result from nitridation of $\mathrm{Nb}$. Because both interdiffusion and oxidation are accelerated at $>350^{\circ} \mathrm{C}$, future tests will focus on the behavior at lower temperatures to determine if the degradation in flux becomes acceptable at some temperature. 


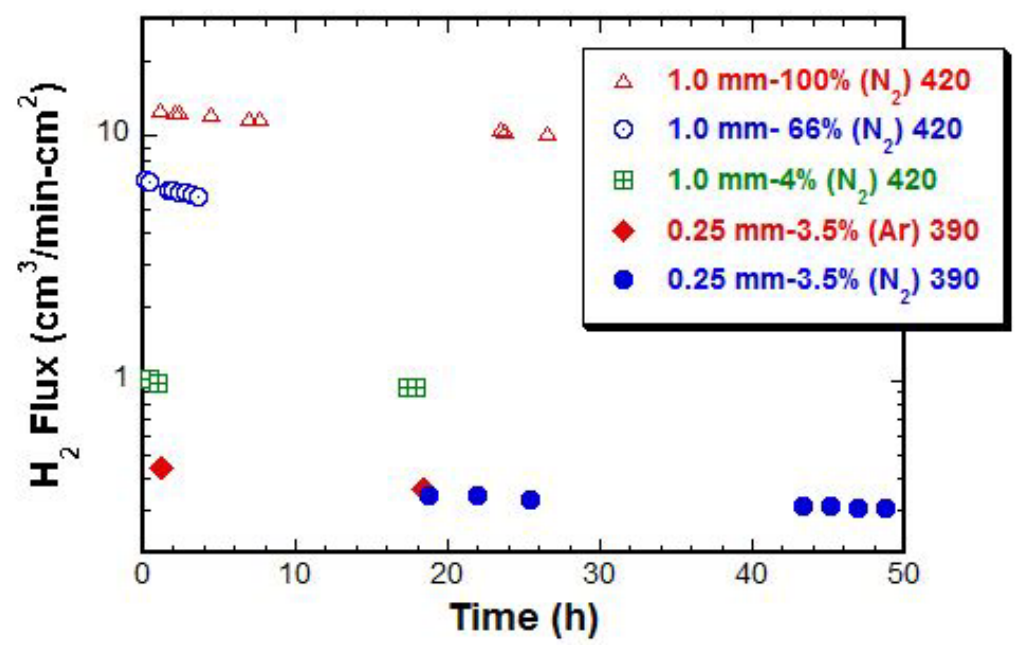

Fig. 1 Hydrogen flux for commercial $\mathrm{Nb}$ foils. Inset gives foil thickness, $\mathrm{H}_{2}$ concentration in feed, composition of sweep gas (in parentheses), and measurement temperature $\left({ }^{\circ} \mathrm{C}\right)$.

It is not clear why the flux for the thin $\mathrm{Nb}$ disk (Fig. 1) was lower than that of the thick disk for the feed gas with $\approx 4 \% \mathrm{H}_{2}$, but the reason might be related to several differences in the tests for the two samples. The thick sample was heated to the measurement temperature under vacuum, whereas the thin sample was heated under flowing Ar. Flowing inert gas might not remove oxygen from the sample chamber as effectively as a vacuum; therefore, the thin sample might have been more susceptible to oxidation during the initial heating. Also, the exposure to oxidation might have been greater for the thin sample because it was tested initially at higher temperature than the thick sample. The fact that the flux decreased as temperature decreased (Fig. 2) supports the idea that the thin sample was influenced by extrinsic factors, such as oxidation or interdiffusion, because measurements by others indicate that Nb's hydrogen permeability should increase as temperature decreases [9].

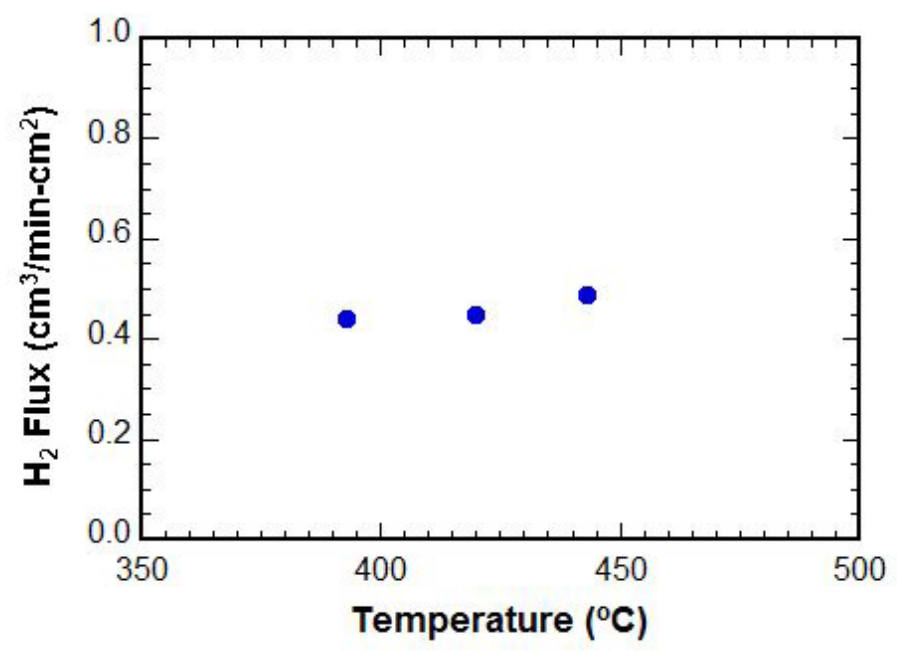

Fig. 2 Hydrogen flux of commercial 0.25-mm-thick $\mathrm{Nb}$ foil measured with 3.5\% $\mathrm{H}_{2} /$ balance He as feed gas and Ar as sweep gas. 
Commercial Ta foil was prepared for testing by lightly polishing, cleaning with isopropyl alcohol, and sputtering Pd onto the foil using a DESK II Sputter unit (Denton Vacuum Inc.). Flux was measured only at low temperatures $\left(<450^{\circ} \mathrm{C}\right)$ because it decreased rapidly at higher temperatures due to undetermined reactions. Seals were made by squeezing an aluminum or graphite ring between the metal foil and the tube, while the assembly was heated to $>300^{\circ} \mathrm{C}$ under vacuum or flowing inert gas. When the temperature exceeded $300^{\circ} \mathrm{C}$, the flow of feed and sweep gas was begun.

Figure 3 shows the time dependence of hydrogen flux for Ta foil (Alfa Aesar) with thickness of $0.25 \mathrm{~mm}$. Before testing, both faces were polished with SiC polishing paper and sputter-coated with Pd for $5 \mathrm{~min}$ at room temperature. The membrane was heated to the measurement temperature $\left(354^{\circ} \mathrm{C}\right)$ under flowing ultrahigh purity (UHP) He. When the sample reached the measurement temperature, the UHP He was replaced with $80 \%$ $\mathrm{H}_{2}$ /balance He on the feed side and UHP Ar on the sweep side. The hydrogen flux had an initial value of $14.3 \mathrm{~cm}^{3} / \mathrm{min}-\mathrm{cm}^{2}$ and decreased relatively quickly in the beginning, but then decreased much more slowly, reaching a value of $11.7 \mathrm{~cm}^{3} / \mathrm{min}-\mathrm{cm}^{2}$ after $46 \mathrm{~h}$.

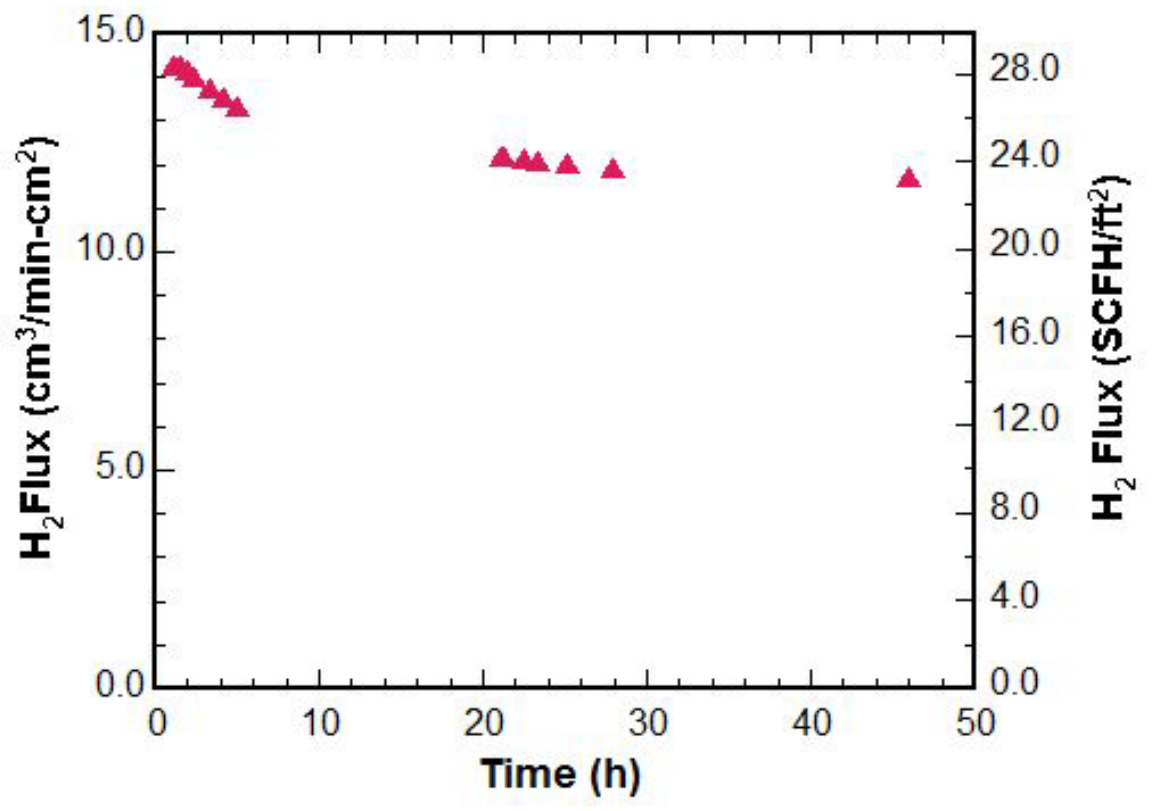

Fig. 3 Hydrogen flux at $354^{\circ} \mathrm{C}$ of $0.25-m m$-thick commercial Ta foil vs. time of exposure to $80 \% \mathrm{H}_{2}$ /balance He as feed and UHP Ar as sweep.

Figure 4 shows the pressure dependence of hydrogen flux at 304 and $354^{\circ} \mathrm{C}$ for the same sample of Ta whose flux is shown in Fig. 3. The flux is plotted versus $\Delta \mathrm{pH}_{2}{ }^{1 / 2}$, i.e., $\sqrt{\mathrm{pH}_{2} \text { (feed) }-} \sqrt{\mathrm{pH}_{2} \text { (sweep) }}$, which was adjusted by varying the sweep gas flow rate to modify $\mathrm{pH}_{2}$ (sweep) while fixing the hydrogen concentration in the feed gas at $80.44 \%$. The flux increased linearly with $\Delta \mathrm{pH}_{2}{ }^{1 / 2}$ at both temperatures, as expected for metallic HTMs, suggesting that the flux might be increased by reducing the membrane thickness. 


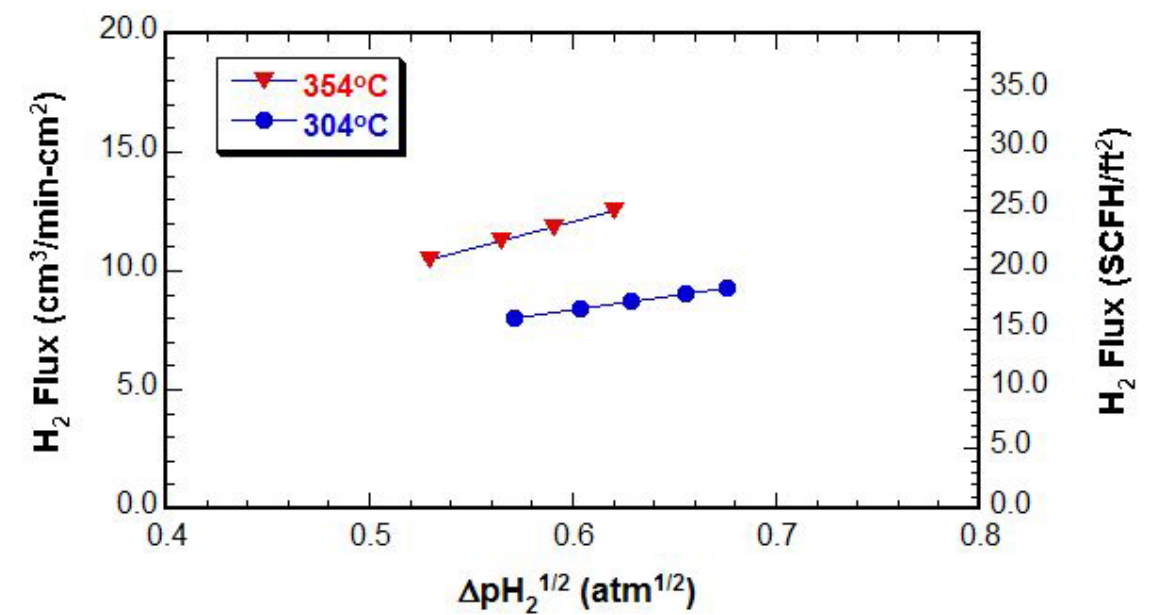

Fig. 4 Hydrogen flux of commercial Ta foil (thickness $=0.25 \mathrm{~mm}$ ) at 304

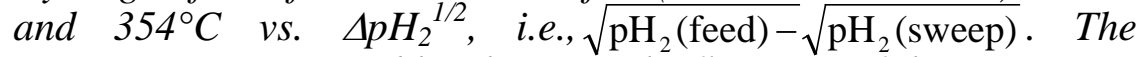
$\mathrm{pH}_{2}$ (sweep) was varied by changing the flow rate of the sweep gas, while $\mathrm{pH}_{2}($ feed) was fixed at $\approx 0.8 \mathrm{~atm}$.

Figure 5 shows the temperature dependence for the flux of the foil measured with $80 \% \mathrm{H}_{2}$ /balance He as feed gas and UHP Ar as sweep gas. These data were obtained after the time dependence was measured at $354^{\circ} \mathrm{C}$ (Fig. 3). The numbers above each data point (Fig. 5) indicate the sequence of the measurements. The decrease in flux with decreasing temperature is similar to our results for $\mathrm{Nb}$ foil but is not predicted on the basis of solubility and diffusivity [10], suggesting that the sample was influenced by extrinsic factors, such as oxidation or interdiffusion between the Ta foil and its Pd coating. Although the Ta foil's temperature dependence resembles that of $\mathrm{Nb}$ foil, initial results suggest that Ta foil is less susceptible to hydrogen embrittlement. To investigate possible differences in their tendency toward embrittlement, we will compare the response of Ta and $\mathrm{Nb}$ foils to cyclical changes in the hydrogen concentration of the feed gas.

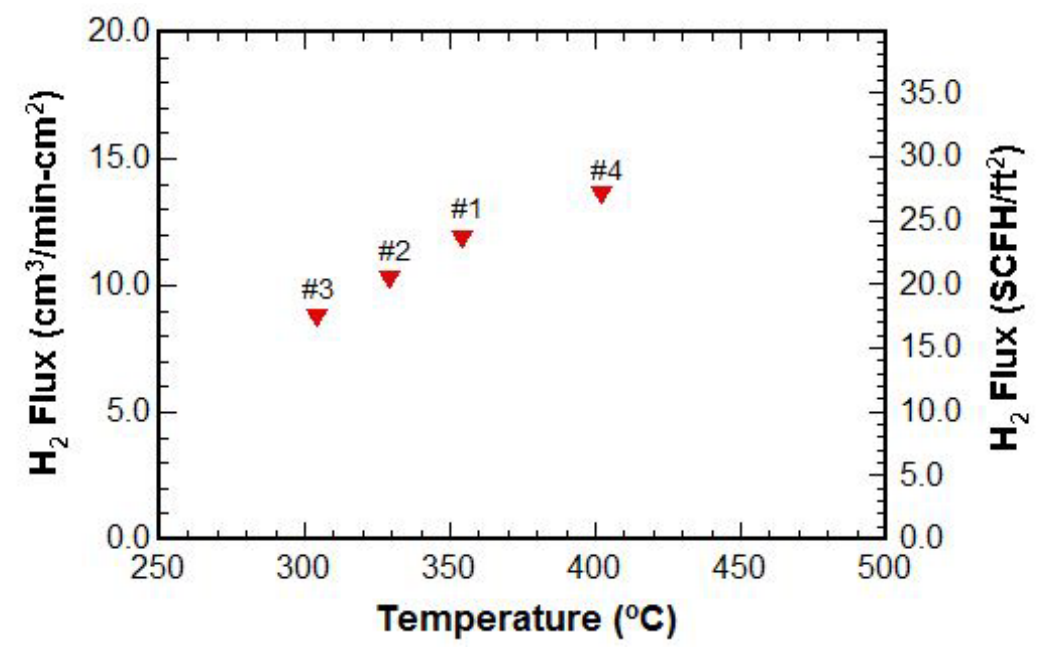

Fig. 5 Hydrogen flux of commercial Ta foil (thickness $=0.25 \mathrm{~mm}$ ) vs. temperature with $80 \% \mathrm{H}_{2}$ /balance He as feed gas and UHP Ar as sweep gas. The numbers above data points indicate the sequence of the measurements. 


\section{Milestone 2. Test tubular thin-film membrane under all test conditions prescribed by the NETL test protocol.}

A protocol for testing hydrogen separation membranes was established at a contractors' review meeting on April 29, 2008, at Morgantown, WV. A high-pressure permeation reactor at Argonne was modified for testing hydrogen separation membranes according to the protocol. A tubular thin-film membrane from Pall Corporation was tested according to the protocol. The membrane $(\approx 4.5 \mathrm{~cm}$ long $x 1.1 \mathrm{~cm}$ O.D.) consisted of a Pd$\mathrm{Au}$ alloy (thickness $\approx 3 \mu \mathrm{m}$ ) on the outside of a $\mathrm{ZrO}_{2}$-buffered, porous stainless steel tube. Stainless steel tubing (0.6 cm O.D.) was welded to each end of the membrane and extended outside the reactor. Gas-tight seals to the extension tubes were made outside of the test reactor at ambient temperature by means of standard compression fittings. Feed gas flowed over the outside of the tube during flux and leakage measurements, while sweep gas flowed through the inside of the tube.

Helium leakage through the membrane was measured before the HTM test protocol began. During leakage measurements, UHP He at a pressure of 200 psig flowed (200 $\left.\mathrm{cm}^{3} / \mathrm{min}\right)$ on the feed side, while UHP Ar flowed $\left(200 \mathrm{~cm}^{3} / \mathrm{min}\right)$ on the sweep side at a total pressure $(\mathrm{He}+\mathrm{Ar})$ of $\approx 20 \mathrm{psig}$. The measured leakage rate at room temperature was $0.28 \mathrm{~cm}^{3} / \mathrm{min}-\mathrm{cm}^{2}$. While continuing to flow He and Ar, the sample was heated $\left(50^{\circ} \mathrm{C} / \mathrm{h}\right)$ to the test temperature $\left(550 \pm 2^{\circ} \mathrm{C}\right)$, and the helium leakage rate was measured again. At $550^{\circ} \mathrm{C}$, the leakage had decreased to $0.15 \mathrm{~cm}^{3} / \mathrm{min}-\mathrm{cm}^{2}$. Subsequently, the hydrogen flux was measured with the feed gas mixtures prescribed in test $1,2 \mathrm{a}, 2 \mathrm{~b}$, and $2 \mathrm{c}$ of the test protocol.

Table 1 summarizes the targeted and actual feed gas compositions during the tests, which differed because He was added for measuring leakage during flux measurements. The feed gas was made by mixing three gases with water delivered by an Eldex 1SMP metering pump. The gases were a certified mixture of $\mathrm{H}_{2} \mathrm{~S}$ (463 ppm) in He, a certified mixture of $\mathrm{H}_{2} / \mathrm{CO} / \mathrm{CO}_{2}$, and UHP He (all from AirGas). Table 2 gives the compositions of the $\mathrm{H}_{2} / \mathrm{CO} / \mathrm{CO}_{2}$ mixtures used for each test. Table 3 gives the flow rates that were used to prepare the feed gas mixtures for the tests. Sierra Smart-Trak Series 100 mass flow controllers, calibrated with Optiflow flow meters, gave the desired flow rates. The flow rate of water was measured gravimetrically.

Flux values were calculated from the average of four measurements of the hydrogen and helium concentrations in the sweep gas. Gas concentrations were measured with an Agilent 6890 Gas Chromatograph (GC). The sweep gas flow rate was measured with a calibrated Optiflow gas flow meter. According to the test protocol, the concentrations of all feed gas components should be measured as the feed exits the reactor, which requires the GC and GC operator to be dedicated solely to this experiment. Under the present circumstances, such an arrangement is not possible; therefore, the $\mathrm{H}_{2}, \mathrm{He}, \mathrm{CO}$, and $\mathrm{CO}_{2}$ concentrations were measured only at the beginning of the day and at the end of the day. During the day, only the $\mathrm{H}_{2}$ and He concentrations were measured. Unless personnel and a new GC can be added, a similar procedure will be followed during typical future runs. 
Table 1. Target and actual feed gas compositions during testing of tubular membrane from Pall Corp. according to HTM test protocol.

\begin{tabular}{|c|c|c|c|c||c|c||c|c||}
\hline & \multicolumn{2}{|c|}{ Test 1} & \multicolumn{2}{c|}{ Test 2a } & \multicolumn{2}{c||}{ Test 2b } & \multicolumn{2}{c|}{ Test 2c } \\
\hline & Target & Actual & Target & Actual & Target & Actual & Target & Actual \\
\hline $\mathrm{H}_{2}(\%)$ & 50.0 & 46.1 & 50.0 & 46.1 & 33.7 & 30.8 & 4.8 & 4.4 \\
\hline $\mathrm{CO}(\%)$ & 1.0 & 0.9 & 1.0 & 0.9 & 1.3 & 1.2 & 2.0 & 1.8 \\
\hline $\mathrm{CO}_{2}(\%)$ & 30.0 & 27.7 & 30.0 & 27.7 & 40.0 & 36.5 & 57.0 & 52.5 \\
\hline $\mathrm{H}_{2} \mathrm{O}(\%)$ & 19.0 & 17.5 & 19.0 & 17.5 & 25.0 & 22.8 & 36.2 & 33.3 \\
\hline $\mathrm{H}_{2} \mathrm{~S}(\mathrm{ppm})$ & 0 & 0 & 20 & 24 & 30 & 27 & 40 & 37 \\
\hline $\mathrm{He}(\%)$ & 0 & 7.8 & 0 & 7.8 & 0 & 8.7 & 0 & 8.0 \\
\hline
\end{tabular}

Table 2. Compositions of $\mathrm{H}_{2} / \mathrm{CO} / \mathrm{CO}_{2}$ certified gas mixtures (mol \%) used to prepare feed gas mixtures for testing tubular membrane from Pall Corp. according to HTM test protocol.

\begin{tabular}{|c|c|c|c|c|}
\hline & Test 1 & Test 2a & Test 2b & Test 2c \\
\hline \hline $\mathrm{H}_{2}$ & Balance & Balance & $45.00 \pm 0.02$ & $7.500 \pm 0.02$ \\
\hline $\mathrm{CO}$ & $1.161 \pm 0.023$ & $1.169 \pm 0.023$ & $1.698 \pm 0.016$ & $3.100 \pm 0.02$ \\
\hline $\mathrm{CO}_{2}$ & $36.93 \pm 0.74$ & $36.80 \pm 0.74$ & Balance & Balance \\
\hline
\end{tabular}

Table 3. Flow rates ( $\mathrm{ml} / \mathrm{min}$ ) of gases used to prepare feed gas mixtures for testing tubular membrane from Pall Corp. according to HTM test protocol.

\begin{tabular}{|c|c|c|c|c|}
\hline & Test 1 & Test 2a & Test 2b & Test 2c \\
\hline \hline $\mathrm{H}_{2} / \mathrm{CO} / \mathrm{CO}_{2}$ (Table 2) & 324 & 324 & 300 & 255 \\
\hline $\mathrm{H}_{2} \mathrm{~S}(463 \mathrm{ppm}) / \mathrm{He}$ & 0 & 22 & 26 & 35 \\
\hline $\mathrm{H}_{2} \mathrm{O}($ steam) & 76 & 76 & 100 & 145 \\
\hline $\mathrm{He}$ & 34 & 12 & 12 & 0 \\
\hline
\end{tabular}


Figure 6 plots the hydrogen flux measured during exposure to the four feed gases prescribed by the HTM test protocol. Figures 7 and 8 plot the purity that was measured during the test. For Fig. 6, the hydrogen flux was calculated from the following equation:

$$
\text { Flux }=\frac{\left[H_{2}^{s}-\left(\mathrm{He}^{s} \bullet \frac{\mathrm{H}_{2}^{f}}{H \mathrm{He}^{f}} \bullet \text { Leak Factor }\right)\right] \bullet \text { Sweep Flow Rate }}{\text { Membrane Area }}
$$

where $H_{2}^{s}, \mathrm{He}^{s}=$ measured $\mathrm{H}_{2}$, He concentrations (\%) in the sweep gas; $\mathrm{H}_{2}^{f}, \mathrm{He}^{f}=\mathrm{H}_{2}$, He concentrations in the feed gas; and the leak Factor (=1.5) corrects for difference in $\mathrm{H}_{2}, \mathrm{He}$ leakage rates.

$$
\text { Purity }(\%)=\frac{\mathrm{H}_{2}^{\mathrm{s}}-\mathrm{CO}_{2}^{\mathrm{s}}-\mathrm{CO}^{\mathrm{s}}-\mathrm{H}_{2} \mathrm{O}^{\mathrm{s}}-\mathrm{CH}_{4}^{\mathrm{s}}-\mathrm{He}^{\mathrm{s}}}{\mathrm{H}_{2}^{\mathrm{s}}} \cdot 100
$$

where $\mathrm{H}_{2}^{\mathrm{s}}, \mathrm{CO}_{2}^{\mathrm{s}}, \mathrm{CO}^{\mathrm{s}}, \mathrm{H}_{2} \mathrm{O}^{\mathrm{s}}, \mathrm{CH}_{4}^{\mathrm{s}}$, and $\mathrm{He}^{\mathrm{s}}$ are the measured concentrations (\%) of components detected in the sweep gas exiting the reactor.

As expected, the hydrogen flux decreased as the hydrogen concentration in the feed gas decreased in proceeding from test 1 to test 2c. The initial hydrogen flux measured during test $2 \mathrm{a}$ was the same as the flux measured during test 1 , because the feed gas compositions were the same except for the small $\mathrm{H}_{2} \mathrm{~S}$ concentration ( $24 \mathrm{ppm}$ ) in test 2a. Due to the presence of $\mathrm{H}_{2} \mathrm{~S}$ (see Table 1), the flux decreased slowly during test 2a, but it stabilized at a value only $\approx 10 \%$ lower than its initial value. We have reported similar behavior for Argonne's cermet membranes during their exposure to $\mathrm{H}_{2} \mathrm{~S}$ concentrations that were not high enough to cause formation of $\mathrm{Pd}_{4} \mathrm{~S}$ [4]. During test $2 \mathrm{~b}$, the flux also decreased $\approx 10 \%$ from its initial value and then appeared to reach a stable value.

The sample's behavior during test 2c differed dramatically from its behavior during tests $1,2 \mathrm{a}$, and $2 \mathrm{~b}$. Whereas the flux (Fig. 6) appeared stable after $\approx 100 \mathrm{~h}$ during tests 1 , $2 \mathrm{a}$, and $2 \mathrm{~b}$, it dropped sharply (within $24 \mathrm{~h}$ ) to zero during test 2c. Likewise, the purity (Fig. 7) decreased quickly during test 2c, but it was stable $(<99.4 \%)$ during test 1 , and its decrease was slow during tests $2 \mathrm{a}$ and $2 \mathrm{~b}$, reaching values of $96.7 \%$ after $\approx 150 \mathrm{~h}$ in test $2 \mathrm{a}$ and $95.2 \%$ after $\approx 100 \mathrm{~h}$ in test $2 \mathrm{~b}$ (Fig. 8). The experimental conditions also changed dramatically during test 2c. The feed pressure dropped from $\approx 200$ to $\approx 95$ psig after the sample was held overnight, and the sweep pressure increased from $\approx 15$ to $\approx 30$ psig, clearly indicating a major increase in leakage that allowed much of the feed gas to flow directly to the sweep side of the membrane. The major increase in leakage is also evident in the sharp drop in purity (Fig. 7) during the same time. In marked contrast, the test conditions remained very stable during tests $1,2 \mathrm{a}$, and $2 \mathrm{~b}$ (Figs. 7 and 8 ).

Argonne's flux values (Fig. 6) were much lower than values reported by Pall Corp. The flux measured at Argonne stabilized at values of 10.8, 9.4, and $6.4 \mathrm{~cm}^{3} / \mathrm{min}-\mathrm{cm}^{2}$ during tests $1,2 \mathrm{a}$, and $2 \mathrm{~b}$, respectively, and it quickly decreased to zero during test $2 \mathrm{c}$. The flux measured at Argonne during test 1 was $21.4 \mathrm{SCFH} / \mathrm{ft}^{2}$ at $550^{\circ} \mathrm{C}$, a much lower value than was reported by Pall. Testing a membrane with 5.5\% Au and using feed gas with a pressure of 170 psig with the composition required for test 1 of the test protocol, Pall reported a hydrogen flux of $400 \mathrm{SCFH} / \mathrm{ft}^{2}$ at $400^{\circ} \mathrm{C}$ [11]. 


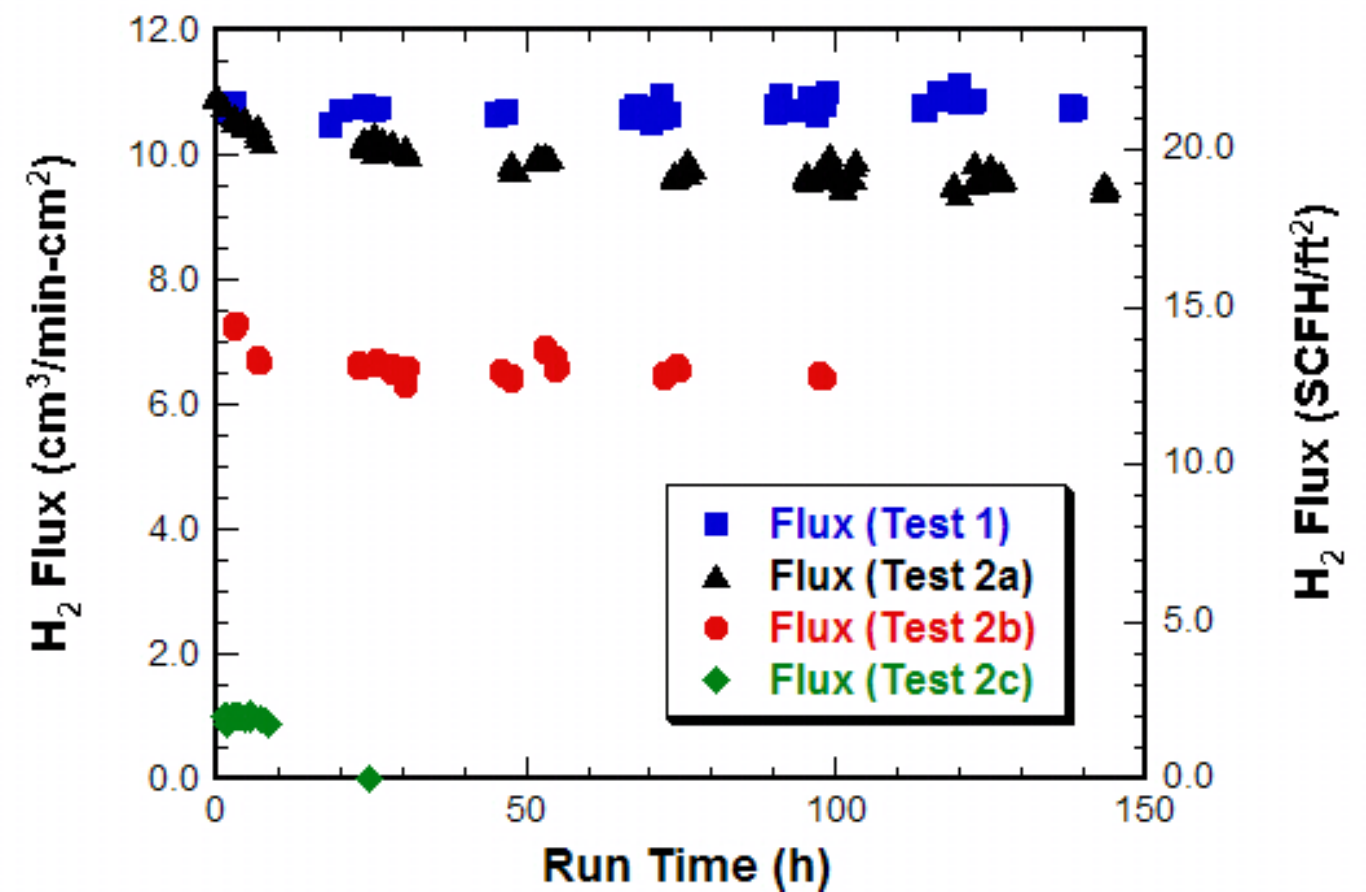

Fig. 6 Hydrogen flux measured at Argonne using tubular Pd-Au alloy membrane from Pall Corp. vs. time during four tests in HTM test protocol.

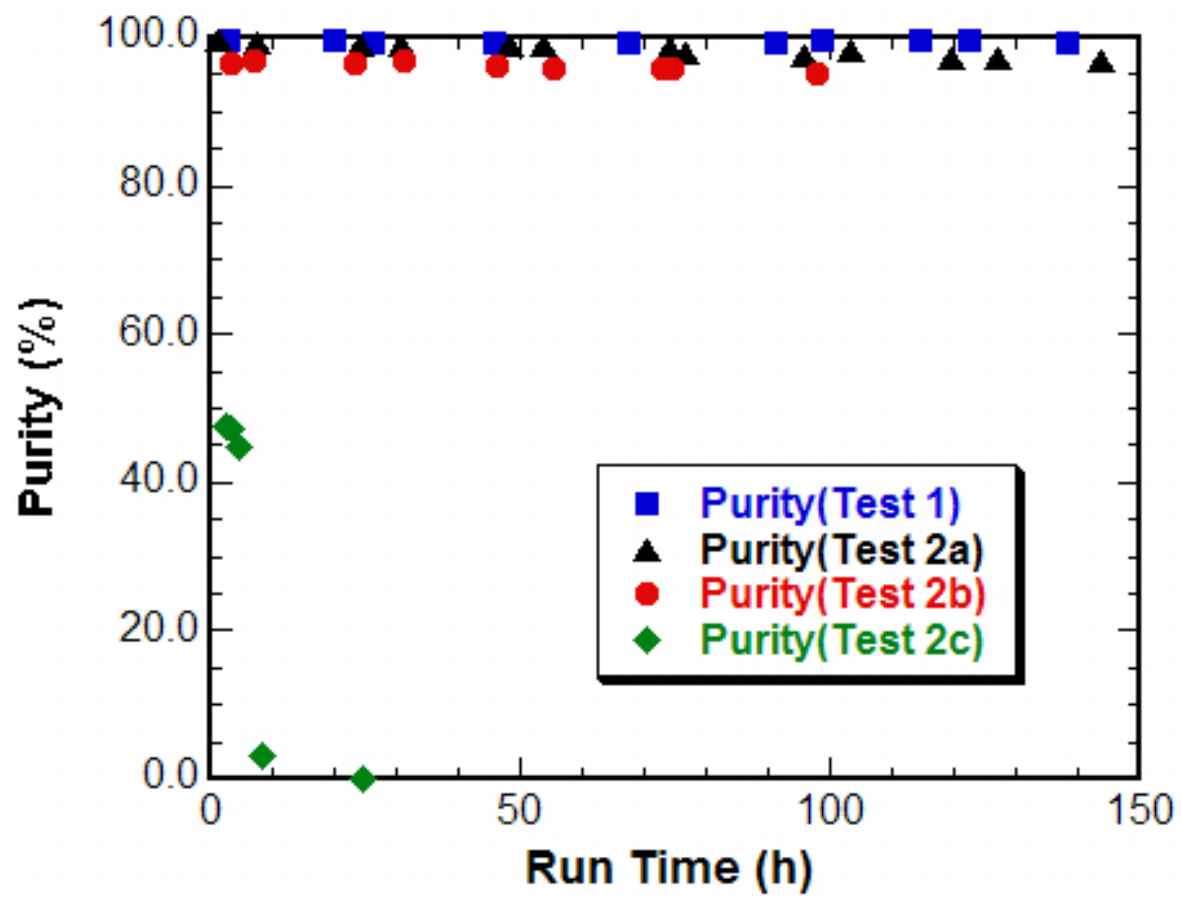

Fig. 7 Hydrogen purity measured at Argonne using tubular Pd-Au alloy membrane from Pall Corp. vs. time during four tests in HTM test protocol. 


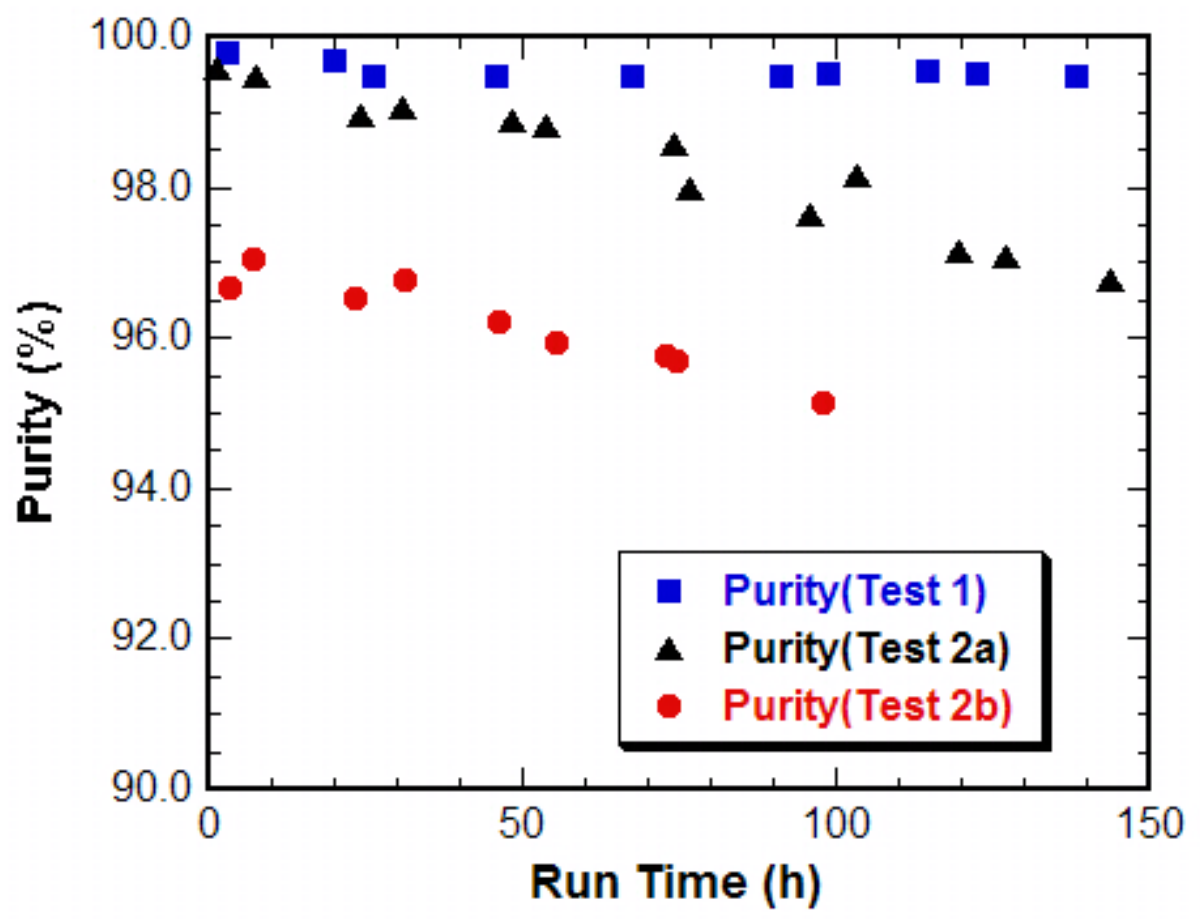

Fig. 8 Hydrogen purity measured at Argonne using tubular Pd-Au alloy membrane from Pall Corp. vs. time during first three of four tests in HTM test protocol. Note range for purity axis is $90 \%-100 \%$.

Our hydrogen flux values differ from those reported by Pall primarily because we used very different gas flow rates during our measurements. The flow rate of feed gas during our measurements was $430-435 \mathrm{~cm}^{3} / \mathrm{min}$, but the results reported by Pall were obtained with a feed gas flow rate that was $\approx 20 \mathrm{X}$ higher $\left(8000 \mathrm{~cm}^{3} / \mathrm{min}\right)$. The flow rate of sweep gas was also much lower $\left(200 \mathrm{~cm}^{3} / \mathrm{min}\right)$ during our measurements, compared to $2000 \mathrm{~cm}^{3} / \mathrm{min}$ during the measurements described by Pall [11]. Low flow rates can contribute to concentration polarization, i.e., depletion of $\mathrm{H}_{2}$ near the feed side of the membrane and accumulation of $\mathrm{H}_{2}$ near the sweep side. Concentration polarization reduces the flux by reducing the effective driving force for permeation. With an active area $\left(15 \mathrm{~cm}^{2}\right)$ considerably larger than that of the HTMs we typically test $\left(1-2 \mathrm{~cm}^{2}\right)$, the tube from Pall was more prone to concentration polarization at the low flow rates that were used. To avoid concentration polarization during future measurements, pending approval from safety officials, Argonne will use higher flow rates when measuring the hydrogen flux for membranes with larger active areas.

\section{Milestone 3. Correlate flux and phase boundary data at low temperatures.}

Palladium foil (Sigma-Aldrich, 99.9\%, thickness $\approx 100 \mu \mathrm{m}$ ) and ANL-3e thin films were used to correlate hydrogen flux measurements at $\approx 540^{\circ} \mathrm{C}$ with $\mathrm{Pd} / \mathrm{Pd}_{4} \mathrm{~S}$ phase boundary data. ANL-3e thin films were made by mixing powders of Pd (70-75 vol. \%) and TZ-3Y (Sigma Aldrich, partially stabilized $\mathrm{ZrO}_{2}$, submicron particle size) and blending the mixture with an organic binder and solvent to produce an ink. Thin films were prepared by painting the ink onto a porous substrate and then sintering. Porous 
substrates were prepared by mixing alumina hydrate powder (Sasol) with manganese oxide (5 mol. \% relative to alumina) sintering aid and an organic binder. Carbon black (Fisher Scientific) and PMMA-CE (Sigma Aldrich, average particle size of $\approx 8 \mu \mathrm{m}$ ) were added as pore formers (total $20 \mathrm{wt}$. \%), and the mixture was uniaxially pressed (5-7 kpsi) into a disk that was heated for $6-8 \mathrm{~h}$ at $900-950^{\circ} \mathrm{C}$ in air to eliminate the pore formers. After the substrate was painted with the ink containing ANL-3e components, it was dried in air and sintered $\left(4 \mathrm{~h}\right.$ at $1350^{\circ} \mathrm{C}$ in air), giving a film thickness of $\approx 20 \mu \mathrm{m}$.

Test samples were mounted onto a spring-loaded test fixture with a gold ring between the sample and the alumina tube that was used to pass sweep gas over the sample. The sample was then heated slowly $\left(2-3^{\circ} \mathrm{C} / \mathrm{min}\right)$ to $920^{\circ} \mathrm{C}$ to soften the gold ring and produce a gas seal. During this process, high purity helium was flowed over the feed side of the sample, and high purity nitrogen was flowed over the sweep side. Leakage through the seal and sample was quantified by measuring the helium concentration in the sweep gas with the GC, and then the reactor temperature was reduced to $540^{\circ} \mathrm{C}$ to begin flux measurements. The exposed surface area of samples during tests was $1.27 \mathrm{~cm}^{2}$.

Before exposing a sample to feed gas with $\mathrm{H}_{2} \mathrm{~S}$, we determined its hydrogen permeability with feed containing 30-33, 50, and 90 vol. $\% \mathrm{H}_{2} /$ balance He by measuring the hydrogen concentration in the sweep gas with the GC. The sample's flux was measured versus time with feed of $30-33 \% \mathrm{H}_{2}$ /balance $\mathrm{He}$, while the $\mathrm{H}_{2} \mathrm{~S}$ concentration was incrementally increased over the range 5-44 ppm $\mathrm{H}_{2} \mathrm{~S}$. The ANL-3e film was tested for 14 days under various $\mathrm{H}_{2} \mathrm{~S}$ concentrations, and the Pd foil was tested for 50 days. After the gas composition was changed, the sample was stabilized with the new composition for 0.5-1 h before hydrogen flux measurements were begun. During several periods, when tests were suspended to calibrate gas sensors in the room, He was flowed on the feed side of the sample, and $\mathrm{N}_{2}$ was flowed on the sweep side.

Feed gases were prepared by blending high purity $\mathrm{H}_{2}$ (99.995\%), UHP He (99.998\%), and 101 ppm $\mathrm{H}_{2} \mathrm{~S} /$ balance He (all from Airgas). Flow rates were controlled with mass flow controllers (MKS 1179A) and were checked two or three times per day with a calibrated flow meter (Agilent 630). The total feed flow rate was $160-180 \mathrm{~cm}^{3} / \mathrm{min}$. Hydrogen flux values were corrected for leakage. The reactor had an interior volume of $\approx 2600 \mathrm{~cm}^{3}$; therefore, the feed gas was expected to attain its targeted composition $\approx 15 \mathrm{~min}$ after a change in the composition; however, a gas was flowed for $\approx 0.5-1.0 \mathrm{~h}$ before the hydrogen flux was measured. Throughout the test, the sample temperature was monitored with a K-type thermocouple placed within 2-3 $\mathrm{mm}$ of the sample.

At the end of a test, the feed gas was switched to high purity He with the sweep gas remaining high purity $\mathrm{N}_{2}$. Both gases flowed at a rate of $\approx 100 \mathrm{~cm}^{3} / \mathrm{min}$ for $\approx 0.5 \mathrm{~h}$ before the sample was cooled to room temperature at $2-3^{\circ} \mathrm{C} / \mathrm{min}$. While cooling, the flow rates of helium and nitrogen were reduced to $50-60 \mathrm{~cm}^{3} / \mathrm{min}$. After the test, the sample was examined by scanning electron microscopy (JEOL 5400) and energy dispersive x-ray spectroscopy (Thermo-Fisher Scientific) for changes in microstructure. 
The Pd foil was first tested with feed gas containing 5 ppm $\mathrm{H}_{2} \mathrm{~S}$ in $30 \% \mathrm{H}_{2}$ /balance He. As shown in Fig. 9, the hydrogen flux was almost stable until feed gas with $10 \mathrm{ppm}$ $\mathrm{H}_{2} \mathrm{~S}$ was introduced, at which point the flux began degrading slowly as the $\mathrm{H}_{2} \mathrm{~S}$ concentration was incrementally increased to $\approx 30 \mathrm{ppm}_{2} \mathrm{~S}$. The flux began degrading more rapidly at $31 \mathrm{ppm}_{2} \mathrm{~S}$ and continued degrading at the higher rate as the $\mathrm{H}_{2} \mathrm{~S}$ concentration was increased to $44 \mathrm{ppm}_{2} \mathrm{~S}$. At $\approx 800 \mathrm{~h}$, the flux had dropped from $\approx 4$ to $\approx 3 \mathrm{~cm}^{3} / \mathrm{min}-\mathrm{cm}^{2}$, at which point the feed was switched to He. After flowing He for $\approx 44 \mathrm{~h}$,

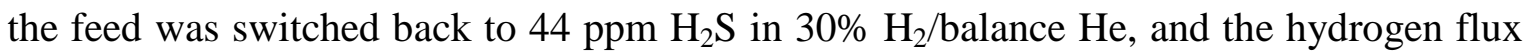

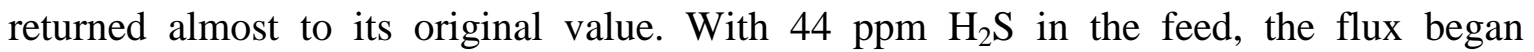
degrading again at the higher rate. The more rapid degradation continued as the $\mathrm{H}_{2} \mathrm{~S}$ concentration was progressively reduced to $32 \mathrm{ppm}$, at which point the flux stabilized and remained stable for about $100 \mathrm{~h}$. Scanning electron microscopy (SEM) examination of the sample after the test (Fig. 10) showed a change in the surface morphology from smooth to rough due to the formation of $\mathrm{Pd}_{4} \mathrm{~S}$. Energy dispersive $\mathrm{x}$-ray spectroscopy (EDS) confirmed that $\mathrm{Pd}_{4} \mathrm{~S}$ had formed, suggesting that the $\mathrm{Pd} / \mathrm{Pd}_{4} \mathrm{~S}$ phase boundary was at 30-32 ppm $\mathrm{H}_{2} \mathrm{~S}$ in $30 \% \mathrm{H}_{2} / \mathrm{He}$ at $540^{\circ} \mathrm{C}$. The slow degradation in flux that was evident with 10$20 \mathrm{ppm}_{2} \mathrm{~S}$ in the feed was probably caused by adsorption of $\mathrm{H}_{2} \mathrm{~S}$ limiting the adsorption of $\mathrm{H}_{2}$, not by formation of $\mathrm{Pd}_{4} \mathrm{~S}$.

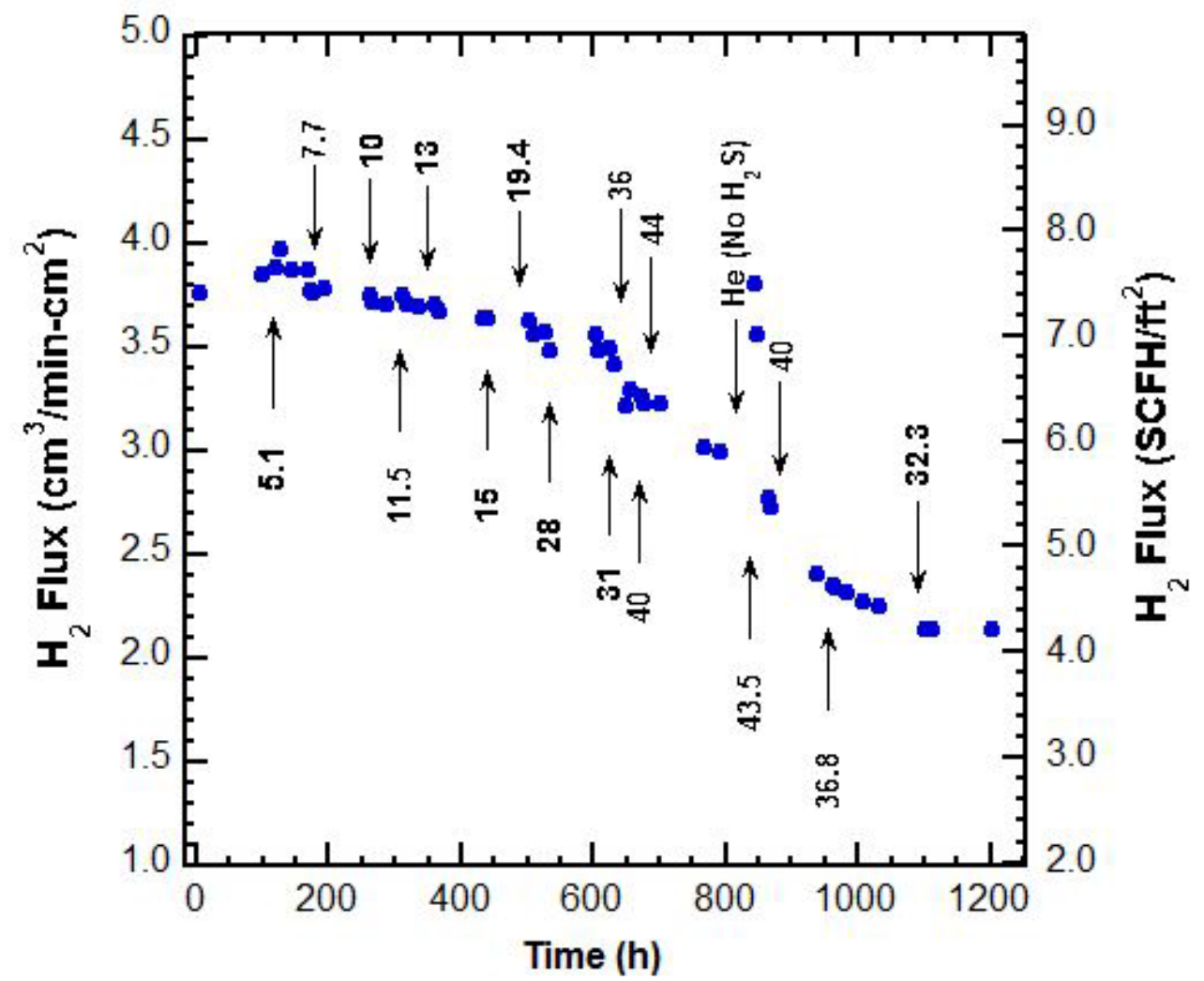

Fig. 9 Hydrogen flux of Pd foil (thickness $\approx 100 \mu \mathrm{m}$ ) at $540^{\circ} \mathrm{C}$ in feed gas with $30 \% \mathrm{H}_{2} / \mathrm{He}$ and various $\mathrm{H}_{2} \mathrm{~S}$ concentrations. Arrows indicate when $\mathrm{H}_{2} \mathrm{~S}$ concentration (ppm) was changed. 


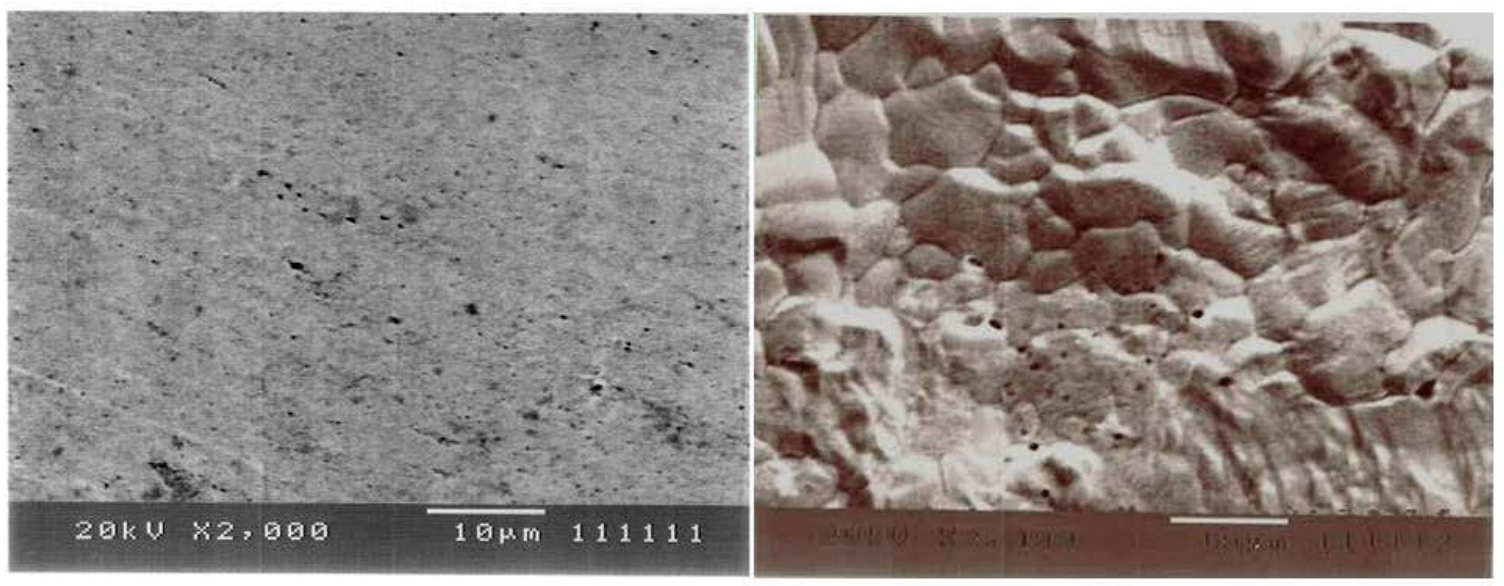

Fig. 10 Plan view of Pd foil before test in 30\% $\mathrm{H}_{2}$ with 5-44 ppm $\mathrm{H}_{2} \mathrm{~S}$ at $540^{\circ} \mathrm{C}$ (on left) and after test (on right).

Figure 11 shows the hydrogen flux of an ANL-3e thin film during testing at $540^{\circ} \mathrm{C}$ with feed of $20 \mathrm{ppm} \mathrm{H}_{2} \mathrm{~S}$ in $33 \% \mathrm{H}_{2}$ /balance He. The flux appeared stable for $\approx 4$ days but dropped sharply during the following 3-day weekend. The feed was then switched to He, and the reactor was flushed for $6 \mathrm{~h}$, but the flux did not return to its initial value, unlike the behavior of the Pd foil (Fig. 9). The thin film's flux nearly returned to its initial value only

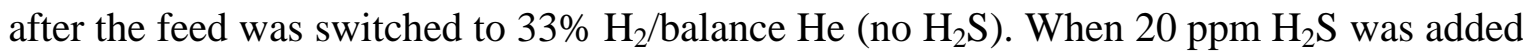
to the feed again, the flux decreased sharply over $\approx 4$ days, confirming that the ANL-3e thin film was not stable under 20 ppm $\mathrm{H}_{2} \mathrm{~S}$ in $33 \% \mathrm{H}_{2} / \mathrm{He}$. Figure 12 shows a fracture surface of the film after the test. While there was no evidence of $\mathrm{Pd}_{4} \mathrm{~S}$ formation, EDS detected $\approx 2-3$ mol. \% sulfur where the feed surface contacted the porous substrate.

In tests with another ANL-3e thin film (Fig. 13), the hydrogen flux dropped $\approx 50 \%$

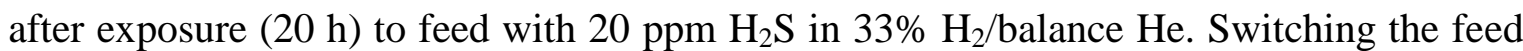
to He for three days did not return the flux to its original value, but the flux recovered after flowing $33 \% \mathrm{H}_{2}$ /balance He (no $\mathrm{H}_{2} \mathrm{~S}$ ) overnight. When $10 \mathrm{ppm}_{2} \mathrm{~S}$ was then added to the feed, the flux decreased quickly to $4.5 \mathrm{~cm}^{3} / \mathrm{min}-\mathrm{cm}^{2}$ but appeared to stabilize. After the sample was exposed to $10 \mathrm{ppm}_{2} \mathrm{~S}$ for $\approx 230 \mathrm{~h}$, the feed was switched to He overnight, and the flux remained unchanged. When the feed was changed to $33 \% \mathrm{H}_{2} / \mathrm{He}$ (no $\mathrm{H}_{2} \mathrm{~S}$ ), the flux returned to its initial value after only $6 \mathrm{~h}$. This test confirmed that the flux of ANL-3e thin films was severely degraded under 20 ppm $\mathrm{H}_{2} \mathrm{~S}$ and did not return to its

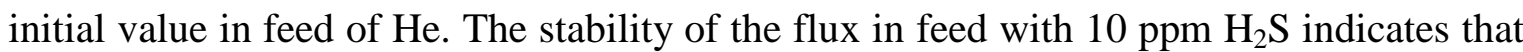

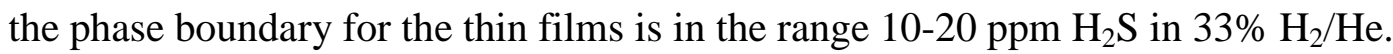

The $\mathrm{Pd} / \mathrm{Pd}_{4} \mathrm{~S}$ phase boundary appeared at a slightly lower $\mathrm{H}_{2} \mathrm{~S}$ concentration for the ANL-3e thin films (10-20 ppm) than for the Pd foil (30-32 ppm). The apparent difference in the phase boundary might have resulted from the porous substrates used for the thin films. Whereas the Pd foil was in direct contact with the feed gas, the porous substrates separated the thin films from the feed gas. Because the thin films had higher flux due to their smaller thickness (20-25 vs. $100 \mu \mathrm{m}$ ) and the substrates impeded gas transport to and from the thin film, concentration polarization was more likely with the thin films. 
Concentration polarization might reduce the effective hydrogen concentration at the feed side of the thin film relative to that for the Pd foil, even though the hydrogen concentration of the feed was slightly higher in tests with thin films $\left(33 \% \mathrm{H}_{2}\right.$ vs. $30 \% \mathrm{H}_{2}$ for the Pd foil). A lower effective hydrogen concentration would shift the $\mathrm{Pd} / \mathrm{Pd}_{4} \mathrm{~S}$ phase boundary toward lower $\mathrm{H}_{2} \mathrm{~S}$ concentration, as was found.

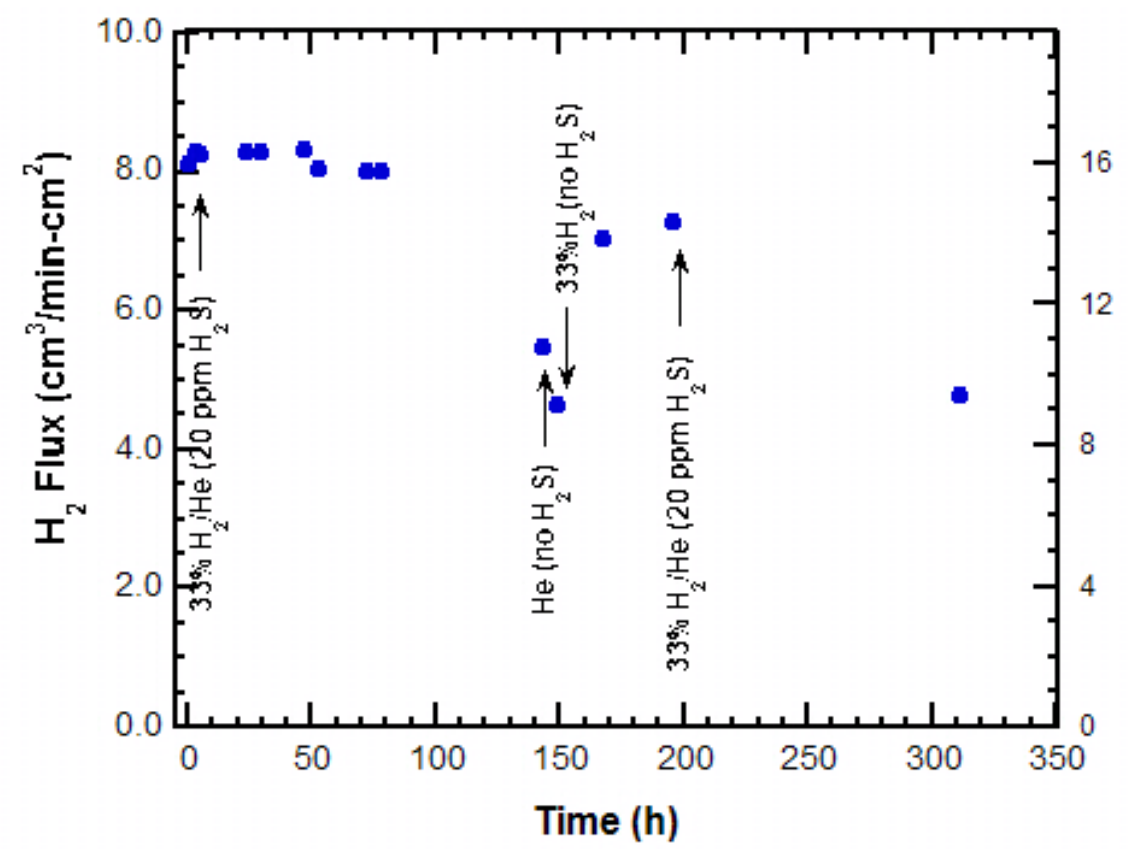

Fig. 11 Hydrogen flux of ANL-3e thin film (thickness $\approx 20 \mu \mathrm{m}$ ) at $540^{\circ} \mathrm{C}$ in feed gas with $20 \mathrm{ppm} \mathrm{H}_{2} \mathrm{~S}$ in $33 \% \mathrm{H}_{2} / \mathrm{He}$, 33\% $\mathrm{H}_{2} / \mathrm{He}$ without $\mathrm{H}_{2} \mathrm{~S}$, and $\mathrm{He}$ without $\mathrm{H}_{2} \mathrm{~S}$. Arrows indicate when feed was changed.

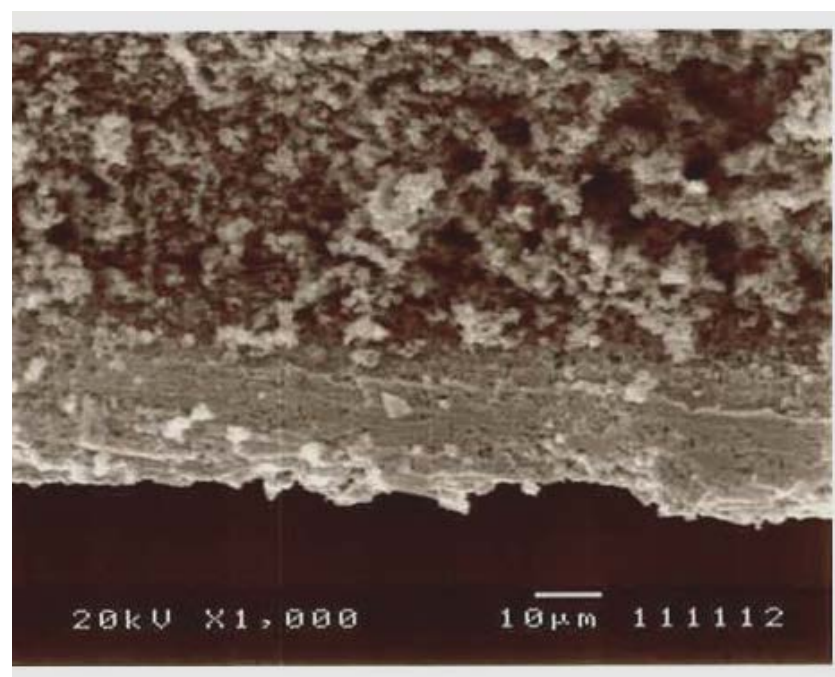

Fig. 12 Fracture surface of ANL-3e thin film (thickness $\approx 20 \mu \mathrm{m}$ ) after test at $540^{\circ} \mathrm{C}$ in feed gas of $33 \% \mathrm{H}_{2}$ and various $\mathrm{H}_{2} \mathrm{~S}$ concentrations. 


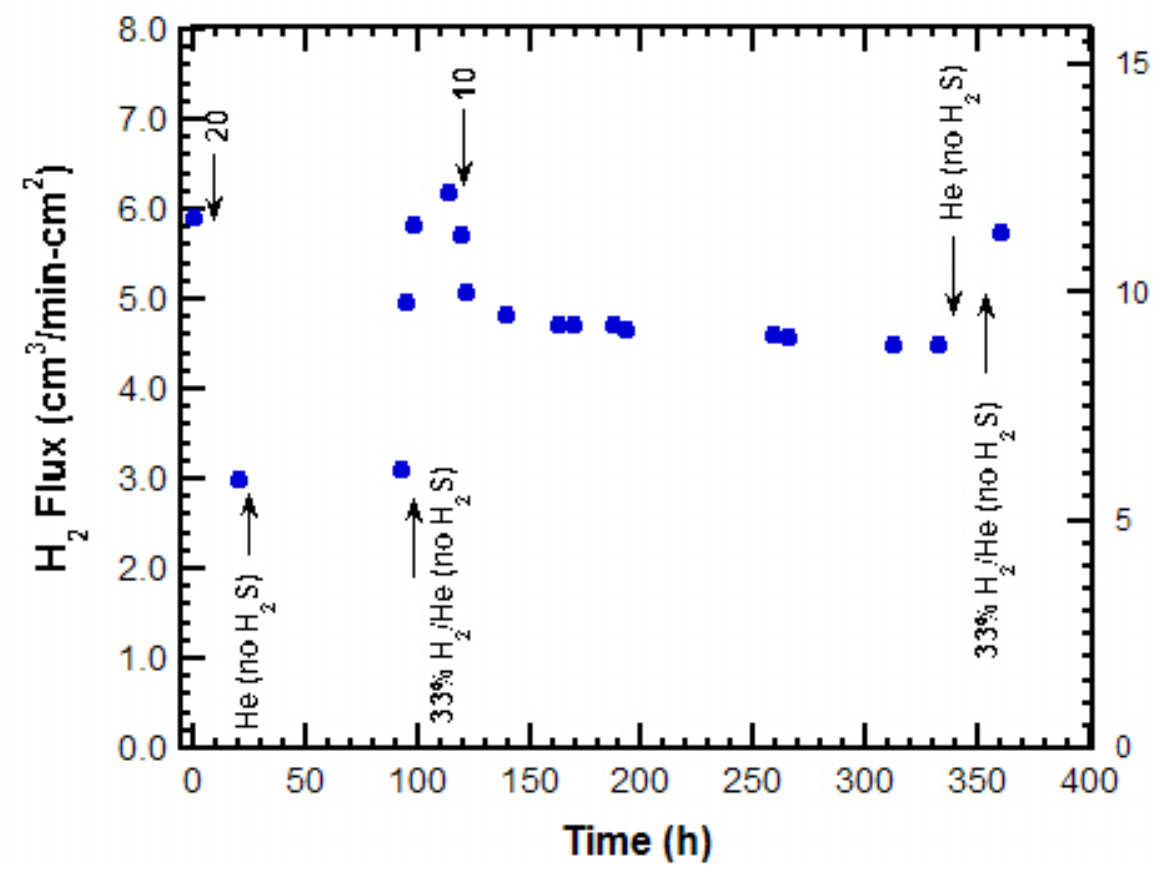

Fig. 13 Hydrogen flux of ANL-3e thin film (thickness $\approx 20 \mu \mathrm{m}$ ) at $540^{\circ} \mathrm{C}$ in feed gas with 10 or $20 \mathrm{ppm} \mathrm{H}_{2} \mathrm{~S}$ in $33 \% \mathrm{H}_{2} / \mathrm{He}$, He without $\mathrm{H}_{2} \mathrm{~S}$, and $33 \% \mathrm{H}_{2} / \mathrm{He}$ without $\mathrm{H}_{2} \mathrm{~S}$. Arrows indicate when feed was changed; numbers give $\mathrm{H}_{2} \mathrm{~S}$ concentration (ppm).

\section{Additional Effort: Monitor hydrogen flux for thin-film ANL-3e membrane during exposure for $\approx \mathbf{4}$ months to simulated "coal gas."}

In addition to the above work, we tested the long-term stability of the thin-film ANL-3e membrane in simulated coal gas. The preparation of the ANL-3e thin film is described above in the discussion of Milestone 3. Mounting of thin-film samples for testing is also described in the discussion of Milestone 3. While the sample was heated to the sealing temperature, high purity (HP) helium flowed over the feed side of the sample and HP nitrogen over the sweep side.

In FY 2009, the hydrogen flux was first measured with $50 \% \mathrm{H}_{2}$ /balance $\mathrm{He}$ as the feed at $400-700^{\circ} \mathrm{C}$, and then cycling tests were done at 400 and $500^{\circ} \mathrm{C}$. The results from the cycling tests were described previously [12]. A cycle began in the morning by flushing the reactor with feed gas of $4 \% \mathrm{H}_{2} /$ balance He flowing at a rate of $150 \mathrm{ml} / \mathrm{min}$ for 30-50 $\mathrm{min}$. The feed was then switched to coal gas ( $51 \% \mathrm{H}_{2} / 31 \% \mathrm{CO}_{2} / 1 \% \mathrm{CO} / 17 \% \mathrm{He}$ ) flowing at a rate of $160 \mathrm{ml} / \mathrm{min}$. Ultra-high purity (UHP) nitrogen flowing at a rate of $150 \mathrm{ml} / \mathrm{min}$ was used as the sweep gas. The feed was switched back to $4 \% \mathrm{H}_{2} /$ balance He $(150$ $\mathrm{ml} / \mathrm{min}$ ) and purged for 25-30 min after the sample had been exposed to coal gas for 5-7 $\mathrm{h}$. The feed was then switched to helium $(80 \mathrm{ml} / \mathrm{min})$ overnight. This cycle was repeated eight times at $400^{\circ} \mathrm{C}$ and then five times at $500^{\circ} \mathrm{C}$. 
After the cycling test at $500^{\circ} \mathrm{C}$, we conducted a long-term ( $\approx 4$ months) stability test. During the stability test, the hydrogen flux was measured in range $400-600^{\circ} \mathrm{C}$ with coal gas $\left(51 \% \mathrm{H}_{2} / 31 \% \mathrm{CO}_{2} / 1 \% \mathrm{CO} / 17 \% \mathrm{He}\right.$ ) at ambient pressure as the feed gas. The coal gas was similar to the feed gas specified by NETL's HTM test protocol set in April 2008, except the pressure was not 200 psig (14 atm), and the gas did not contain 19 vol. $\% \mathrm{H}_{2} \mathrm{O}$. The coal gas was used "dry" (i.e., without adding any moisture) or "wet" (i.e., the coal gas was bubbled through a water at room temperature to give $\approx 2.6 \mathrm{~mol} . \% \mathrm{H}_{2} \mathrm{O}$ in the feed gas). Because the high pressure reactor needed for conducting the protocol tests is being used to measure leakage through thin-film tubes, the test described here was done instead. The ANL-3e membranes will be tested again soon according to the HTM test protocol.

The gas flow rates during the hydrogen flux measurements were quantified and adjusted by using an Agilent Optiflow 630 flow meter before each analysis of the sweep gas. The feed gas composition was adjusted by using mass flow controllers (MKS 1179A) to blend gas containing $61.68 \% \mathrm{H}_{2} / 37.12 \% \mathrm{CO}_{2} / 1.2 \% \mathrm{CO}$ with UHP helium (99.998\%). During the test, the feed gas flowed at a rate of $160 \mathrm{ml} / \mathrm{min}$, and the sweep gas (UHP nitrogen) at a rate of $150 \mathrm{ml} / \mathrm{min}$. With a reactor volume of $\approx 2600 \mathrm{~cm}^{3}$, the feed gas was expected to attain its targeted composition $\approx 15$ min after a new feed gas began flowing; however, the sample was allowed to stabilize for $\approx 1-2 \mathrm{~h}$ before the hydrogen flux was measured following a change in temperature or feed gas composition. During periods when the test was suspended to test gas sensors in the laboratory, He and $\mathrm{N}_{2}$ continued flowing on the feed and sweep side of the sample, respectively. The hydrogen flux was determined by analyzing the concentrations of hydrogen and other components in the sweep gas with an Agilent 6890 Gas Chromatograph (GC). The concentrations of He, CO, $\mathrm{H}_{2} \mathrm{O}$, and $\mathrm{CO}_{2}$ were measured to determine leakage and selectivity for the membrane.

Figure 14 shows the sequence of flux measurements during the $\approx 4$ months of testing with an ANL-3e thin-film disk. Up to 100 days, the feed during the measurements was dry coal gas $\left(51 \% \mathrm{H}_{2} / 31 \% \mathrm{CO}_{2} / 1 \% \mathrm{CO} / 17 \% \mathrm{He}\right)$ at $500^{\circ} \mathrm{C}$, then $600^{\circ} \mathrm{C}$, then $550^{\circ} \mathrm{C}$. After 100 days, the feed was wet coal gas $\left(\approx 2.6 \mathrm{~mol} . \% \mathrm{H}_{2} \mathrm{O}\right)$ at $550^{\circ} \mathrm{C}$, then $500^{\circ} \mathrm{C}$. After 125 days, the feed was dry coal gas at $400^{\circ} \mathrm{C}$. Figure 15 plots the same results versus the elapsed time at each temperature.

During measurements at $500^{\circ} \mathrm{C}$ in dry coal gas, the hydrogen flux decreased sharply but quickly returned to its original value when the feed gas was switched to helium (at $\approx 100 \mathrm{~h}$ and $\approx 500 \mathrm{~h}$ in Fig. 15). Recovery of the original flux value was observed twice, after the flux had decreased $\approx 20 \%$ following the initial exposure to coal gas and after it had decreased $\approx 40 \%$ following a longer exposure.

After measuring the flux at $500^{\circ} \mathrm{C}$ with dry coal gas, we measured it with feed gas of $50 \% \mathrm{H}_{2}$ /balance He over the range $400-700^{\circ} \mathrm{C}$. Flux values with $50 \% \mathrm{H}_{2} /$ balance He were identical before and after the stability test at $500^{\circ} \mathrm{C}$ (Fig. 16). The reproducibility of the flux values measured before and after exposure to coal gas, like the recovery in flux values at $500^{\circ} \mathrm{C}$ when helium was the feed gas, indicates that the degradation in flux is reversible. 


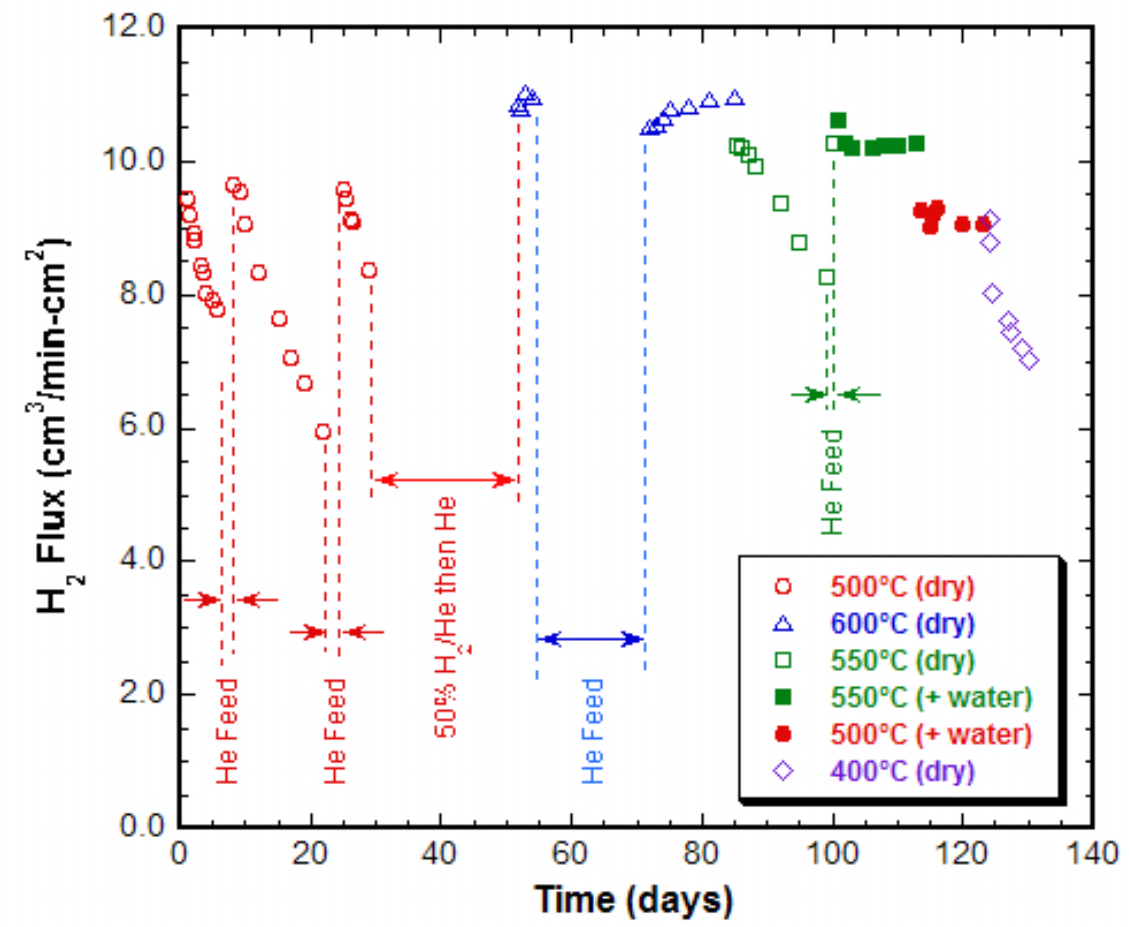

Fig. 14 Hydrogen flux during long-term stability test of ANL-3e thin film at different temperatures in coal gas (51\% $\left.\mathrm{H}_{2} / 31 \% \mathrm{CO}_{2} / 1 \% \mathrm{CO} / 17 \% \mathrm{He}\right)$.

After measuring the hydrogen flux with coal gas and $50 \% \mathrm{H}_{2} /$ balance He at $500^{\circ} \mathrm{C}$, we monitored the flux for $\approx 300 \mathrm{~h}$ at $600^{\circ} \mathrm{C}$ with dry coal gas as the feed. The flux was stable during the entire test at $600^{\circ} \mathrm{C}$, showing even a slight increase from its initial value $\left(\approx 10.5 \mathrm{~cm}^{3} / \mathrm{min}-\mathrm{cm}^{2}\right)$. By contrast, the flux again decreased with exposure time when the temperature was lowered to $550^{\circ} \mathrm{C}$; however, the flux decreased more slowly at $550^{\circ} \mathrm{C}$ than it did at $500^{\circ} \mathrm{C}$. The flux decreased $\approx 20 \%$ from its initial value $\left(\approx 10.2 \mathrm{~cm}^{3} / \mathrm{min}-\mathrm{cm}^{2}\right)$ over a period of $\approx 350 \mathrm{~h}$ at $550^{\circ} \mathrm{C}$, but the flux decreased $\approx 20 \%$ in only $\approx 100 \mathrm{~h}$ at $500^{\circ} \mathrm{C}$. When the feed was switched to He from coal gas at $550^{\circ} \mathrm{C}$, the flux returned to its initial value after only $\approx 18 \mathrm{~h}$. Clearly, temperature strongly influences the effect of coal gas on the hydrogen flux. Figures 14 and 15 suggest that HTMs using pure Pd might be suitable at $\geq 550^{\circ} \mathrm{C}$ but are susceptible to contaminants at lower temperatures. Palladium-based alloys might be suitable for applications at temperatures $<550^{\circ} \mathrm{C}$, as the alloys are reported [5] to be more resistive than pure Pd to the effect of contaminants.

The reproducible recovery in flux after exposure to He (Figs. 14 and 15) shows that a reversible process, such as $\mathrm{CO}$ and/or $\mathrm{CO}_{2}$ adsorption, caused the degradation in flux during exposure to coal gas. Others report that $\mathrm{CO}$ impedes hydrogen permeation through Pd and some Pd alloy membranes [5, 6] by occupying adsorption sites for hydrogen and that temperature strongly affects the decrease in flux. Tests involving feed gas at reduced pressure [5] showed that CO completely prevented hydrogen permeation through $\mathrm{Pd}$ at $100^{\circ} \mathrm{C}$ but had no effect on permeation at $\approx 400^{\circ} \mathrm{C}$. Another possible cause of the decrease in flux, deposition of coke on the membrane, seems unlikely because it is doubtful that exposing the membrane to dry He would eliminate coke from the membrane's surface. 


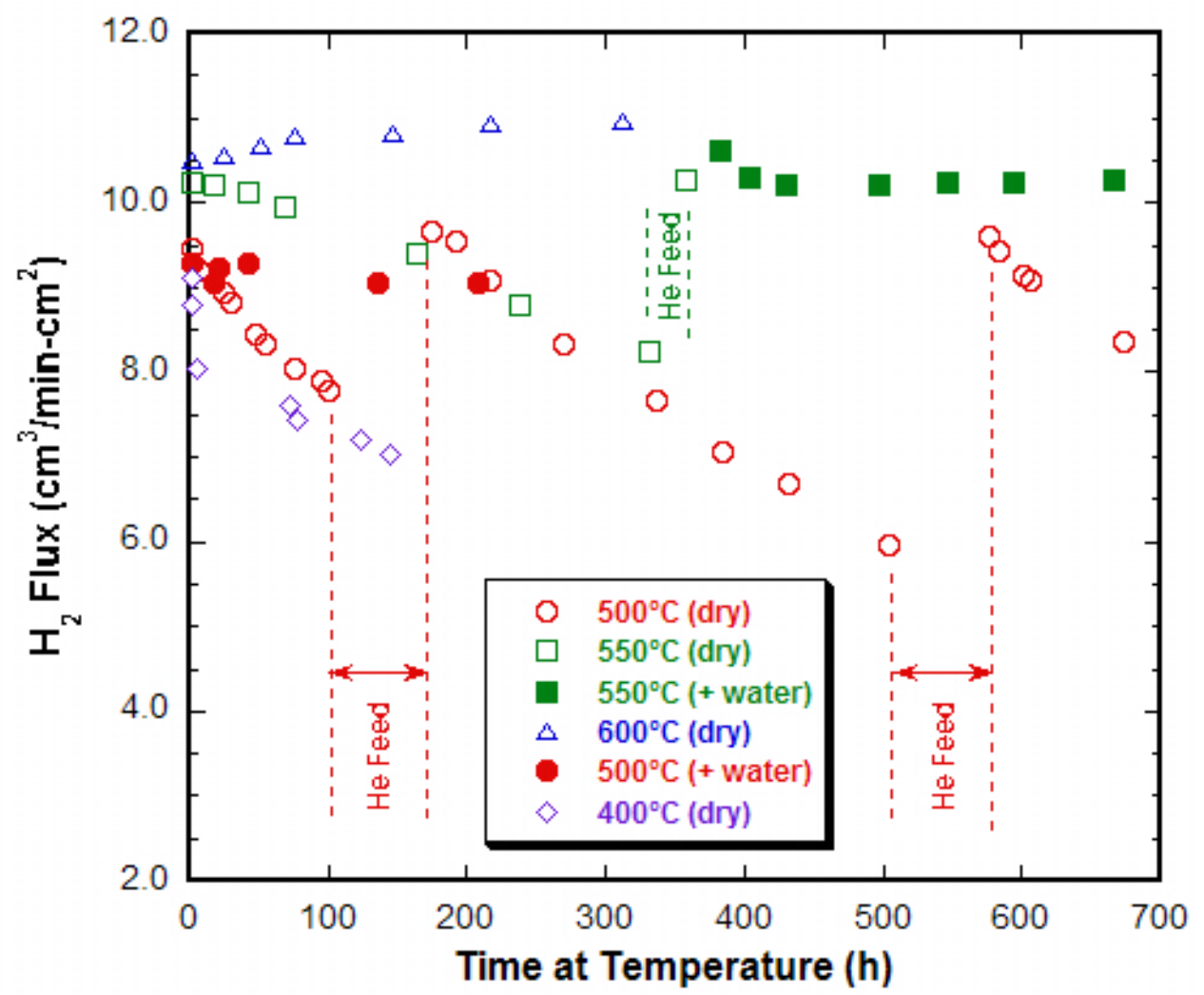

Fig. 15 Hydrogen flux vs. time of ANL-3e thin film at different temperatures during long-term stability test in coal gas ( $51 \% \mathrm{H}_{2} / 31 \% \mathrm{CO}_{2} / 1 \% \mathrm{CO} / 17 \% \mathrm{He}$ ).

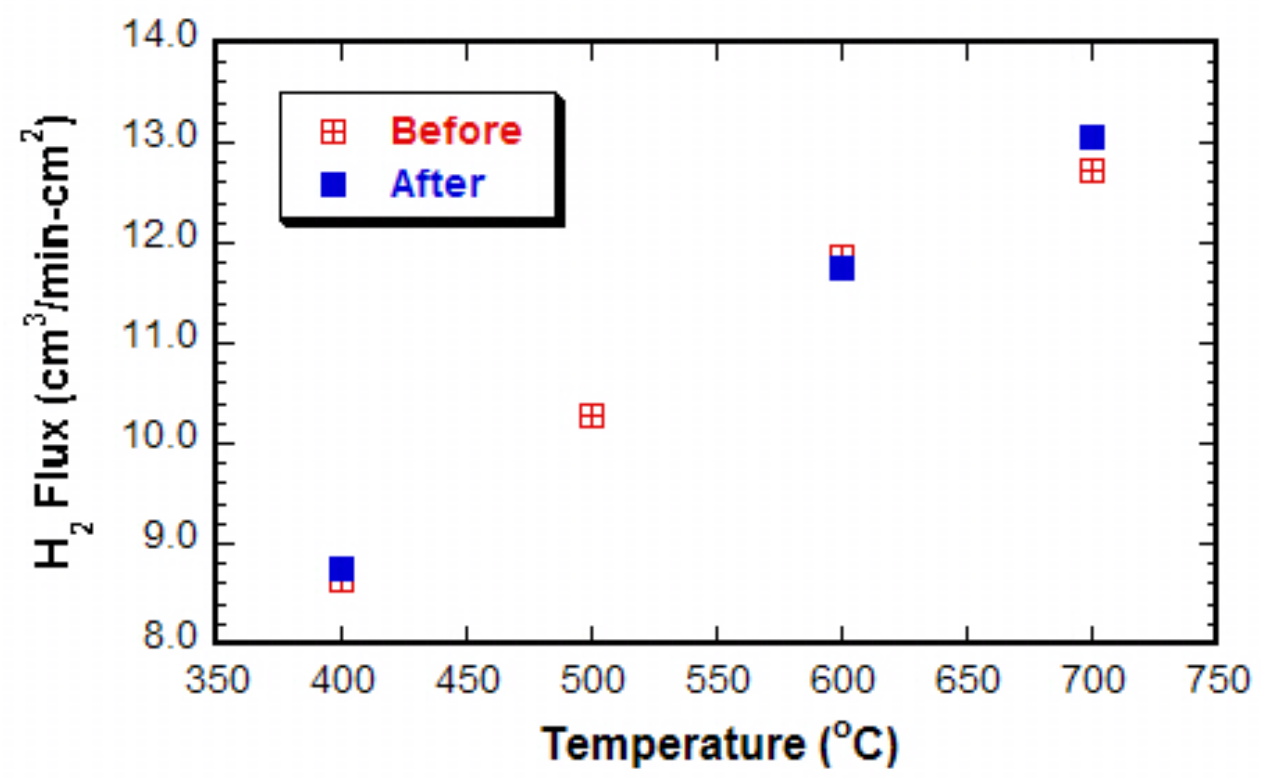

Fig. 16 Hydrogen flux measured with feed of $50 \% \mathrm{H}_{2} /$ balance He before and after testing stability of ANL-3e thin film for $\approx 700 \mathrm{~h}$ at $500^{\circ} \mathrm{C}$ in coal gas $\left(51 \% \mathrm{H}_{2} / 31 \% \mathrm{CO}_{2} / 1 \% \mathrm{CO} / 17 \% \mathrm{He}\right)$. 
The hydrogen flux was unaffected by exposure to wet coal gas $\left(\approx 2.6 \mathrm{~mol} . \% \mathrm{H}_{2} \mathrm{O}\right)$ at $500^{\circ} \mathrm{C}$ and $550^{\circ} \mathrm{C}$. The flux in wet coal gas was equivalent to the initial flux in dry coal gas, but the flux was stable for $>300 \mathrm{~h}$ when the feed was wet, whereas the flux decreased sharply in dry coal gas at all test temperatures. Likewise, the flux dropped quickly and reproducibly at $500^{\circ} \mathrm{C}$ with dry coal gas but was stable when moisture was added to the feed. Flux stability with wet coal gas might result from a lower CO concentration via the water-gas shift reaction:

$$
\mathrm{CO}+\mathrm{H}_{2} \mathrm{O} \leftrightarrow \mathrm{CO}_{2}+\mathrm{H}_{2}
$$

Analysis of feed gas exiting the reactor confirmed that the $\mathrm{CO}$ concentration was lower in wet coal gas than in dry gas. The flow rate of CO in the effluent was $\approx 1.4 \mathrm{~cm}^{3} / \mathrm{min}$ in wet coal gas and $\approx 2.4 \mathrm{~cm}^{3} / \mathrm{min}$ in dry coal gas. Hydrogen finds less competition for adsorption sites in feed gas with a lower $\mathrm{CO}$ concentration. On the other hand, if adsorption of $\mathrm{CO}_{2}$ were the cause of the flux decreasing in dry gas, adding water would exacerbate, not eliminate, the flux degradation because adding water increases the $\mathrm{CO}_{2}$ concentration through Eqn. 3.

The GC analysis of the sweep stream revealed leakage of $\mathrm{He}$ and $\mathrm{CO}_{2}$ but not $\mathrm{CO}$. These new results show that neither $\mathrm{He}$ nor $\mathrm{CO}_{2}$ leakage increased during the exposures at 400 and $500^{\circ} \mathrm{C}$. From measured $\mathrm{He}$ and $\mathrm{CO}_{2}$ leakages (Fig. 17), the $\mathrm{H}_{2} / \mathrm{CO}_{2}$ selectivity $\left(\mathrm{S}_{\mathrm{H}_{2} / \mathrm{CO}_{2}}\right)$ and $\mathrm{H}_{2} / \mathrm{He}$ selectivity $\left(\mathrm{S}_{\mathrm{H}_{2} / \mathrm{He}}\right)$ were calculated from the following equations:

$$
\mathrm{S}_{\mathrm{H}_{2} / \mathrm{CO}_{2}}=\frac{\mathrm{H}_{2} \text { (sweep) } / \mathrm{H}_{2} \text { (feed) }}{\mathrm{CO}_{2} \text { (sweep) } / \mathrm{CO}_{2} \text { (feed) }} \quad \mathrm{S}_{\mathrm{H}_{2} / \mathrm{He}}=\frac{\mathrm{H}_{2} \text { (sweep) } / / \mathrm{H}_{2} \text { (feed) }}{\mathrm{He} \text { (sweep) } / \mathrm{He} \text { (feed) }}
$$

Figure 18 shows the $\mathrm{H}_{2} / \mathrm{CO}_{2}$ and $\mathrm{H}_{2} /$ He selectivities during the long-term test.

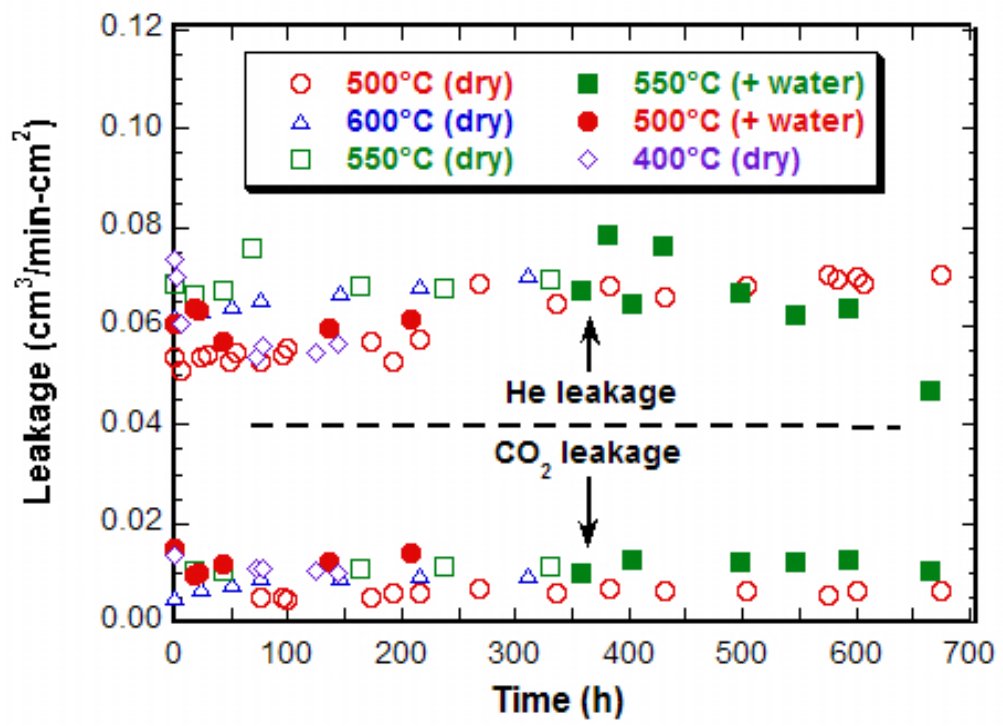

Fig. 17 Leakage of He and $\mathrm{CO}_{2}$ at different temperatures during long-term stability test of ANL-3e thin film in coal gas $\left(51 \% \mathrm{H}_{2} / 31 \% \mathrm{CO}_{2} / 1 \% \mathrm{CO} / 17 \% \mathrm{He}\right)$. 

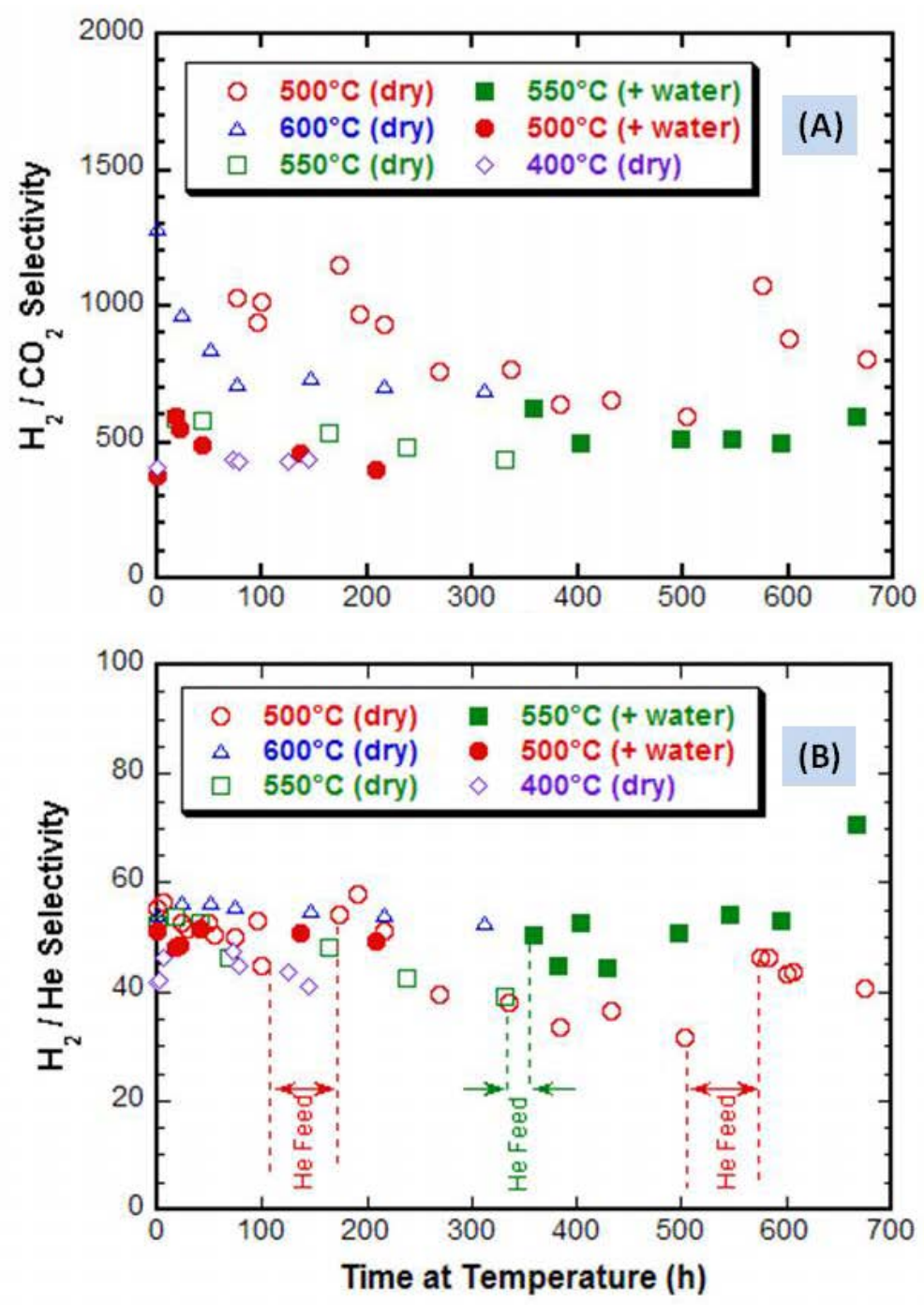

Fig. 18 a) $\mathrm{H}_{2} / \mathrm{CO}_{2}$ selectivity and b) $\mathrm{H}_{2} /$ He selectivity of ANL-3e thin film during long-term ( $\approx 4$ months) stability test of ANL-3e thin film at $400-600^{\circ} \mathrm{C}$.

Helium leakage increased slowly ( 0.05 to $0.07 \mathrm{~cm}^{3} / \mathrm{min}-\mathrm{cm}^{2}$ ) during measurements at $500^{\circ} \mathrm{C}$, but then was almost constant (Fig. 17). It decreased when water was added to the feed at $550^{\circ} \mathrm{C}$ and nearly equaled its initial value $\left(0.05 \mathrm{~cm}^{3} / \mathrm{min}-\mathrm{cm}^{2}\right)$ during the final measurements at $400^{\circ} \mathrm{C}$. The $\mathrm{CO}_{2}$ leakage remained stable at all temperatures during the test, increasing only slightly from $<0.005 \mathrm{ml} / \mathrm{min}^{-\mathrm{cm}^{2}}$ at $500^{\circ} \mathrm{C}$ to $0.012 \mathrm{ml} / \mathrm{min}-\mathrm{cm}^{2}$ after $\approx 100$ days, when water was added to the feed at $550^{\circ} \mathrm{C}$. Even though the concentration of $\mathrm{CO}_{2}$ in the feed gas was twice that of $\mathrm{He}, \mathrm{CO}_{2}$ leakage was lower than He leakage because $\mathrm{CO}_{2}$ molecules are larger than He atoms. The much higher values of $\mathrm{H}_{2} / \mathrm{CO}_{2}$ selectivity compared with $\mathrm{H}_{2} / \mathrm{He}$ selectivity (Fig. 18) reflect that the $\mathrm{CO}_{2}$ leakage was considerably lower despite its higher concentration in the feed gas. It is not known what fraction of the leakage, if any, passed through the sample and what part passed through the seal. 


\section{FUTURE WORK}

Development of ANL-3e Thin-Film Membranes. We will work to improve the properties of thin-film ANL-3e membranes. Paste painting is an effective method for depositing HTM thin films, but the incidence of pinholes increases as the membrane area increases, which will become important as tubular ANL-3e membranes are made. Adding a sintering aid increases the density of thin films but does not eliminate pinholes entirely. Colloidal spray deposition and infiltration techniques will be used to seal pinholes in thin films. Thin-film membranes (thickness $\leq 20 \mu \mathrm{m}$ ) will be tested at pressures up to $200 \mathrm{psig}$ in Argonne's high pressure reactor, first using $\mathrm{H}_{2} / \mathrm{He}$ mixtures and then following the NETL test protocol. When tubular membranes are tested, the hydrogen flux and permeability will be measured versus the sweep and feed gas flow rates to determine whether concentration polarization is a significant factor.

After testing ANL-3e membranes according to the test protocol, several additional characteristics of the thin films will be evaluated to assess the practicality of the thin films during large-scale gas separations. The reproducibility of the thin-film membrane's performance will be evaluated by testing multiple thin-film samples under test protocol conditions. The stability of thin-film membranes will be tested by measuring flux versus time under fixed, high-flux, test protocol conditions, and the scalability of the membranes will be evaluated by measuring the flux of thin-film tubular membranes with an active membrane area having larger active area $\left(\approx 15 \mathrm{~cm}^{2}\right.$ vs. $\left.\approx 1.3 \mathrm{~cm}^{2}\right)$. At the conclusion of these tests, a thin-film membrane will be fabricated with sufficient active area to produce $2 \mathrm{lb}(0.9 \mathrm{~kg}) \mathrm{H}_{2} /$ day, and the membrane will be tested in a gasifier slip stream.

System Analyses. A third party, to be identified by DOE, will evaluate the economics of an integrated gasification and combined cycle (IGCC) system for hydrogen production that employs HTMs for hydrogen purification. In the evaluation, the economics of an IGCC system operating at $900^{\circ} \mathrm{C}$ will be compared to one operating at $400^{\circ} \mathrm{C}$. In addition to identifying novel equipment, estimating its cost, and considering challenges with interfacing the equipment with the overall system, opportunities to improve the overall process will be explored. In particular, heat source temperature, pressure and duty requirements, heat carrier medium, and conditions and purity of the process streams will be considered. While most of the plant will be based on wellunderstood equipment, user modules for the HTM units will need to be developed, because HTMs represent a departure from commonly used equipment.

Evaluation of process issues and economics will continue as technical progress warrants. As directed though consultations with NETL's program managers, contacts will be made and discussions will be held with potential collaborators. We will work with NETL's in-house R\&D team and their Systems Engineering Group to validate the process concept and conduct techno-economic evaluation of proton-conducting membrane technology for separating hydrogen in the power and petrochemical industries. We will provide technical input and engineering data to the NETL team to develop models for process viability and for thermal management studies. 


\section{PUBLICATIONS AND PRESENTATIONS}

Transport Properties of $\mathrm{BaCe}_{0.95} \mathrm{Y}_{0.05} \mathrm{O}_{3-\alpha}$ Mixed Conductors for Hydrogen Separation, Solid State Ionics, 100, 45 (1997).

Development of Mixed-Conducting Oxides for Gas Separation, Solid State Ionics, 108, 363 (1998).

Development of Proton-Conducting Membranes, presented at the AIChE Annual Meeting, New Orleans, LA, March 9-13, 1998.

Mixed-Conducting Ceramic Membranes for Hydrogen Separation, presented at the 193 ${ }^{\text {rd }}$ Meeting of the Electrochemical Society, San Diego, CA, May 3-8, 1998.

Development of Mixed-Conducting Ceramic Membranes for Hydrogen Separation, Ceramic Transactions, 92, 1 (1998).

Development of Mixed-Conducting Dense Ceramic Membranes for Hydrogen Separation, Proc. $5^{\text {th }}$ Intl. Conf. Inorganic Membranes, Nagoya, Japan, June 22-26, 1998, pp. 192-195.

Development of Proton-Conducting Membranes for Hydrogen Separation, presented at the Advanced Coal-based Power and Environmental Systems '98 Conference, Morgantown, WV, July 21-23, 1998.

The Effects of Dopants and A:B Site Nonstoichiometry on Properties of Perovskite-Type Proton Conductors, J. Electrochem. Soc., 145, 1780 (1998).

Transport Properties of $\mathrm{SrCe}_{0.95} \mathrm{Y}_{0.05} \mathrm{O}_{3-\alpha}$ and its Application for Hydrogen Separation, Solid State Ionics, 110, 303 (1998).

High-Temperature Deformation of $\mathrm{BaCe}_{1-\mathrm{x}} \mathrm{Y}_{\mathrm{x}} \mathrm{O}_{3-\mathrm{y}}(0.05<\mathrm{x}<0.2)$, Solid State Ionics, $\underline{117}$, 323 (1999).

Development of Mixed-Conducting Ceramics for Gas Separation Applications, Mat. Res. Soc. Symp. Proc., 548, 545 (1999).

Performance Testing of Hydrogen Transport Membranes at Elevated Temperatures and Pressures, presented at Symposium on Hydrogen Production, Storage, and Utilization, New Orleans, Aug. 22-26, 1999; Am. Chem. Soc., Fuel Chem. Div., 44(4), 914 (1999).

Development of Mixed-Conducting Ceramic Membrane for Hydrogen Separation, presented at Sixteenth Annual International Pittsburgh Coal Conference, Pittsburgh, PA, Oct. 11-15, 1999.

Characterization of Ceramic Hydrogen Separation Membranes Containing Various Nickel Concentrations, presented at the Conference on Fossil Energy Materials -- Critical Supporting Technology R\&D for Vision 21, Knoxville, TN, April 24-25, 2000.

Mixed Proton-Electron Conducting Cermet Membranes for Hydrogen Separation, presented at $102^{\text {nd }}$ Annual Mtg. of the American Ceramic Society, St. Louis, MO, April 30-May 3, 2000. 
Effect of Surface Modification on Hydrogen Permeation of $\mathrm{Ni}-\mathrm{BaCeO}_{3} \mathrm{Composites}$ presented at $102^{\text {nd }}$ Annual Mtg. of the American Ceramic Society, St. Louis, MO, April 30-May 3, 2000.

Effect of Surface Modification on Hydrogen Permeation of Ni-BaY $\mathrm{Ce}_{1-\mathrm{x}} \mathrm{O}_{3-\delta}$ Composites, presented at $197^{\text {th }}$ Meeting of the Electrochemical Society, Toronto, Ontario, Canada, May 14-19, 2000.

Evaluation and Modeling of a High-Temperature, High Pressure, Hydrogen Separation Membrane for Enhanced Hydrogen Production from the Water-Gas Shift Reaction, in "Advances in Hydrogen Energy," eds., C. E. G. Padro and F. Lau, Kluwer Academic/Plenum, New York, pp. 93-110 (2000).

Characterization of Ceramic Hydrogen Separation Membranes with Varying Nickel Concentrations, J. of Applied Surface Science, 167, 34 (2000).

The Crystal Structures and Phase Transitions in Y-doped $\mathrm{BaCeO}_{3}$ : Their Dependence on Y-Concentration and Hydrogen Doping, Solid State Ionics, 138, 63 (2000).

Development of Dense Ceramic Membranes for Hydrogen Separation, Proc. 26th International Conference on Coal Utilization and Fuel Systems, Clearwater, FL, March 58, 2001, pp. 751-761.

Thin-Film Cermet Membrane Preparation for Hydrogen Separation, presented at 103 Annual Meeting of the American Ceramic Society, Indianapolis, IN, April 22-25, 2001.

Surface Modifications of Hydrogen-Separation Membranes Based on the Mixed Conductor Ni-BCY, presented at 103 ${ }^{\text {rd }}$ Annual Meeting of the American Ceramic Society, Indianapolis, IN, April 22-25, 2001.

Development of Dense Ceramic Membranes for Hydrogen Separation, published in the Proceedings of the $6^{\text {th }}$ Natural Gas Conversion Symposium, Girdwood, Alaska, June 1722, 2001.

Development of Dense Ceramic Membranes for Hydrogen Separation, Proceedings of the $18^{\text {th }}$ International Pittsburgh Coal Conference, Newcastle, Australia, Dec. 4-7, 2001, published by the Pittsburgh Coal Conference, University of Pittsburgh, Pittsburgh, PA.

Defect Chemistry Modeling of High-Temperature Proton-Conducting Cerates, Solid State Ionics, $\underline{149}, 1$ (2002).

Current Status of Dense Ceramic Membranes for Hydrogen Separation, Proceedings of the 27th International Technical Conference on Coal Utilization and Fuel Systems, Clearwater, FL, March 4-7, 2002, published by the Coal Technology Association, Gaithersburg, MD.

Dense Ceramic Membranes for Hydrogen Separation, presented at the $16^{\text {th }}$ Annual Conference on Fossil Energy Materials, Baltimore, MD, April 22-24, 2002.

Hydrogen Production by High-Temperature Water Splitting Using Mixed Oxygen IonElectron Conducting Membranes, Proc. 201 ${ }^{\text {st }}$ Electrochem. Soc. Mtg., Philadelphia, PA, May 12-17, 2002. 
Effect of Pd Coating on Hydrogen Permeation of Ni-Barium Cerate Mixed Conductor, Electrochemical and Solid-State Letters, 5 (3), J5 (2002).

Electrical Properties of p-type Electronic Defects in the Protonic Conductor $\mathrm{SrCe}_{0.95} \mathrm{Eu}_{0.05} \mathrm{O}_{3-\delta}$, J. Electrochem. Soc., $\underline{150}$ (6), A790 (2003).

Interfacial Resistances of Ni-BCY Mixed-Conducting Membranes for Hydrogen Separation, Solid State Ionics, 159, 121 (2003).

Defect Structure and n-Type Electrical Properties of $\mathrm{SrCe}_{0.95} \mathrm{Eu}_{0.05} \mathrm{O}_{3-\delta}$, J. Electrochem. Soc., 150, A1484 (2003).

Hydrogen Production by Water Splitting Using Mixed Conducting Membranes, Proc. National Hydrogen Assoc. 14th Annual U.S. Hydrogen Meeting, Washington, DC, March 4-6, 2003.

Current Status of Mixed-Conducting Ceramic Membranes for Gas Separation Applications, presented at the Univ. of Houston, March 14, 2003.

Dense Cermet Membranes for Hydrogen Separation, presented at the 225th Amer. Chem. Soc. Natl. Mtg., Fuel Chemistry Div., New Orleans, March 23-27, 2003.

Hydrogen Production by Water Dissociation Using Mixed-Conducting Membranes, presented at 225th Amer. Chem. Soc. Natl. Mtg., Fuel Chemistry Div., New Orleans, March 23-27, 2003.

Current Status of Mixed-Conducting Ceramic Membranes for Gas Separation Applications, presented at the University of Illinois, Urbana-Champaign, April 24, 2003.

Hydrogen Production by Water Dissociation Using Oxygen-Permeable Cermet Membranes, presented at 105th Ann. Mtg. of Amer. Ceramic Soc., Nashville, April 27-30, 2003.

Preparation and Characterization of New Mixed Conducting Oxides $\mathrm{Ba}\left(\mathrm{Zr}_{0.8-\mathrm{x}} \mathrm{Pr}_{\mathrm{x}} \mathrm{Y}_{0.2}\right) \mathrm{O}_{2.9}$, presented at 105th Ann. Mtg. of Amer. Ceramic Soc., Nashville, April 27-30, 2003.

Metal/Ceramic Composites with High Hydrogen Permeability, U.S. Patent \#6,569,226, May 27, 2003.

Current Status of Dense Cermet Membranes for Hydrogen Separation, presented at the 20th Annual Intl. Pittsburgh Coal Conf., Pittsburgh, Sept. 15-19, 2003; in Conf. Proc., S46, 187.PDF, 2003.

Current Status of Ceramic Membranes for Hydrogen Production and Separation Applications, presented at the U. of Alaska-Fairbanks, Sept. 24, 2003.

Hydrogen Production by Water Dissociation Using Mixed Conducting Membranes, presented at Second Information Exchange Meeting on Nuclear Production of Hydrogen, Argonne Natl. Lab., Oct. 2-3, 2003.

A Method to Remove Ammonia using a Proton-Conducting Membrane, U.S. Patent \#6,630,116, Oct. 7, 2003.

Numerical Modeling of Hydrogen Permeation in Chemical Potential Gradients, Solid State Ionics, 164, 107 (2003). 
Development of Dense Cermet Membranes for Hydrogen Separation, presented at the 204th Mtg. of the Electrochemical Soc., Orlando, Oct. 12-17, 2003.

Hydrogen Permeation of Cermet $\mathrm{Ba}\left(\mathrm{Ce}_{0.6} \mathrm{Zr}_{0.2}\right) \mathrm{Y}_{0.2} \mathrm{O}_{3} / \mathrm{Ni}$ Membranes, presented at the 204th Mtg. of the Electrochemical Soc., Orlando, Oct. 12-17, 2003.

Hydrogen Permeability of $\mathrm{SrCe}_{1-\mathrm{x}} \mathrm{M}_{\mathrm{x}} \mathrm{O}_{3-\mathrm{d}}(\mathrm{x}=0.05, \mathrm{M}=\mathrm{Eu}, \mathrm{Sm})$, Solid State Ionics, $\underline{167}$, 99 (2004).

Use of Mixed Conducting Membranes to Produce Hydrogen by Water Dissociation, Intl. J. Hydrogen Energy, 29, 291-296 (2004).

Hydrogen Production by Water Dissociation using Mixed-Conducting Ceramic Membranes, Proc. of National Hydrogen Assoc. 15 ${ }^{\text {th }}$ Annual U.S. Hydrogen Energy Conf., Los Angeles, CA, April 27-30, 2004.

Mixed-Conducting Dense Ceramic Membranes for Hydrogen Production and Separation from Methane, presented at $15^{\text {th }}$ World Hydrogen Energy Conf., Yokohama, Japan, June 27-July 2, 2004.

Hydrogen Production from Water Using Mixed-Conducting Ceramic Membranes, presented at $15^{\text {th }}$ World Hydrogen Energy Conf., Yokohama, Japan, June 27-July 2, 2004.

Development of Dense Ceramic Membranes for Hydrogen Production and Separation, Proc. of $8^{\text {th }}$ Intl. Conf. on Inorganic Membranes, eds., F. T. Akin and Y. S. Lin, Adams Press, Chicago, IL (2004), pp. 163-166.

Development of Dense Cermet Membranes for Hydrogen Separation, presented at $21^{\text {st }}$ Annual Intl. Pittsburgh Coal Conf., Osaka, Japan, Sept. 13-17, 2004.

Hydrogen Permeation of Cermet [Ni-Ba( $\left.\left(\mathrm{Ce}_{0.6} \mathrm{Zr}_{0.2}\right) \mathrm{Y}_{0.2} \mathrm{O}_{3-\delta}\right]$ Membranes, presented at the 206 th Mtg. of the Electrochemical Soc., Honolulu, Oct. 3-8, 2004.

Development of Dense Ceramic Membranes for Hydrogen Production and Separation, presented at American Soc. for Materials--Annual Materials Solution Conf., Columbus, OH, Oct. 18-21, 2004.

Electrical and Hydrogen Transport Properties of $\mathrm{SrCe}_{0.8} \mathrm{Yb}_{0.2} \mathrm{O}_{3-\delta} / \mathrm{Ni}$ Cermet Membranes, presented at Fall Meeting of Materials Research Society, Boston, Nov. 29-Dec. 3, 2004.

Preparation and Hydrogen Pumping Characteristics of $\mathrm{BaCe}_{0.8} \mathrm{Y}_{0.2} \mathrm{O}_{3-\delta}$ Thin Film, presented at Fall Meeting of Materials Research Society, Boston, Nov. 29-Dec. 3, 2004.

Hydrogen Permeability and Microstructure Effect of Mixed Protonic-Electronic Conducting Eu-Doped Strontium Cerate, J. Mater. Sci., 40, 4061-4066 (2005).

Defect Structure and Transport Properties of Ni-SrCeO ${ }_{3-\delta}$ Cermet for Hydrogen Separation Membrane, J. Electrochem. Soc. 152(11), J125 (2005).

Dense Cermet Membranes for Hydrogen Separation, presented at American Institute of Chemical Engineers (AIChE) Spring National Meeting, Atlanta, GA, April 10-14, 2005.

Hydrogen Separation Using Dense Cermet Membranes, presented at $30^{\text {th }}$ Intl. Tech. Conf. on Coal Utilization and Fuel Systems, Clearwater, FL, April 17-21, 2005. 
Electrical and Hydrogen Transport Properties of $\mathrm{SrCe}_{0.8} \mathrm{Yb}_{0.2} \mathrm{O}_{3-8} / \mathrm{Ni}$ Cermet Membranes, Mat. Res. Soc. Symp. Proc., 3ㅗ, K3.2 (2005).

Preparation and Hydrogen Pumping Characteristics of $\mathrm{BaCe}_{0.8} \mathrm{Y}_{0.2} \mathrm{O}_{3-\delta}$ Thin Film, Mat. Res. Soc. Symp. Proc., 835, K1.5 (2005).

Structure, Proton Incorporation and Transport Properties of Ceramic Proton Conductor $\mathrm{Ba}\left(\mathrm{Ce}_{0.7} \mathrm{Zr}_{0.2} \mathrm{Yb}_{0.1}\right) \mathrm{O}_{3-\mathrm{d}}$, Mat. Res. Soc. Symp. Proc., $\underline{835}$ K1.4 (2005).

Development of Dense Ceramic Membranes for Hydrogen Separation, presented at 2005 DOE Annual Hydrogen Program Review, Washington, DC, May 23-25, 2005.

Membranes: The Good, The Bad, and The Ugly, presented to Hydrogen \& Fuel Cell Tech. Prog. Office, DOE, Wash., DC, June 8, 2005.

Thin Film Preparation and Hydrogen Pumping Characteristics of $\mathrm{BaCe}_{0.8} \mathrm{Y}_{0.2} \mathrm{O}_{3-\delta}$, Solid State Ionics, 176, 1479-1484 (2005).

Hydrogen Production by Water Splitting Using Dense Thin-Film Cermet Membranes, presented at Fall Meeting Materials Research Society, Boston, Nov. 28-Dec. 2, 2005.

Hydrogen Permeation and Chemical Stability of Cermet [Ni-Ba $\left(\mathrm{Zr}_{0.8-\mathrm{x}} \mathrm{Ce}_{\mathrm{x}} \mathrm{Y}_{0.2}\right) \mathrm{O}_{3}$ ] Membranes, Electrochem. \& Solid State Lett., 8(12), J35-J37 (2005).

Electrochemical Hydrogen Pumping Characteristics of $\mathrm{BaCe}_{0.8} \mathrm{Y}_{0.2} \mathrm{O}_{3-\delta}$ Thin Film, presented at Electrochem. Soc. 2005 Fall Mtg., Los Angeles, Oct. 16-21, 2005.

Defect Structure and Transport Properties of $\mathrm{Ni}-\mathrm{SrCeO}_{3-\delta}$ Cermet for Hydrogen Separation Membrane, J. Electrochem. Soc., 152 (11), J125, 2005.

Review: Stress-Induced Diffusion and Cation Defect Chemistry Studies of Perovskites, invited paper published in "Defects \& Diffusion in Ceramics - An Annual Retrospective VII: Defect \& Diffusion Forum," Scitec Publication, London, UK (Oct. 2005), pp. 43-63.

Hydrogen Production by Water Dissociation Using Mixed Oxygen Ion-Electron Conducting Membranes, presented at Electrochem. Soc. 2005 Fall Mtg., Los Angeles, Oct. 16-21, 2005.

Hydrogen Permeation of Ceramic/Metal Composite Thin Films, presented at Electrochem. Soc. 2005 Fall Mtg., Los Angeles, Oct. 16-21, 2005.

Development of Dense Cermet Membranes for Hydrogen Separation, invited presentation at World Hydrogen Technologies Convention, Singapore, Oct. 3-6, 2005.

Mixed-Conducting Dense Ceramic Membranes for Air Separation and Natural Gas Conversion, J. Solid State Electrochem., 10, 617-624 (2006).

Hydrogen Separation by Dense Cermet Membranes, Fuel, 85(2), 150-155 (2006).

Hydrogen Production by Water Dissociation Using Mixed-Conducting Dense Ceramic Membranes, invited presentation at Amer. Chem. Soc. $231^{\text {st }}$ Natl. Mtg., Atlanta, March 26-30, 2006. 
Development of Dense Membranes for Hydrogen Production and Separation, Invited Talk at the $2^{\text {nd }}$ Energy Center Hydrogen Initiative Symposium, Purdue University, West Lafayette, IN, April 12-13, 2007.

Development of Dense Cermet Membranes for Hydrogen Separation, presented at AIChE Spring Mtg., Orlando, FL, April 23-27, 2006.

Hydrogen Production from Methane Using Dense Oxygen and Hydrogen Transport Membranes, presented at 209th Electrochemical Soc. Mtg., Denver, May 7-12, 2006.

Development of Dense Hydrogen Transport Membranes, presented at the $31^{\text {st }}$ International Technical Conference on Coal Utilization and Fuel Systems, Clearwater, FL, May 21-25, 2006.

Annealing Effect of Cermet Membranes on Hydrogen Permeability, Chem. Lett., 35(12), 1378-1379 (2006).

Mixed-conducting Membranes for Hydrogen Production and Separation, Invited presentation at 2006 MRS Fall Meeting, Boston, MA, Nov. 27 - Dec. 1, 2006.

Dense Cermet Membranes for Hydrogen Separation from Mixed Gas Streams, presented at $23^{\text {rd }}$ Annual Intl. Pittsburgh Coal Conf., Pittsburgh, PA, Sept. 25-28, 2006.

Effect of Zr-Doping on the Chemical Stability and Hydrogen Permeation of the Ni$\mathrm{BaCe}_{0.8} \mathrm{Y}_{0.2} \mathrm{O}_{3-\partial}$ Mixed Protonic-Electronic Conductor, Chemistry of Materials, 18(19), 4647 (2006).

Composite Ni-Ba $\left(\mathrm{Zr}_{0.1} \mathrm{Ce}_{0.7} \mathrm{Y}_{0.2}\right) \mathrm{O}_{3}$ Membrane for Hydrogen Separation, J. Power Sources, $\underline{159}$ (2), 1291 (2006).

Stability of Dense Cermet Membranes for Hydrogen Separation, presented at $211^{\text {th }}$ Meeting of Electrochemical Society, Chicago, IL, May 6-10, 2007.

Development of Dense Membranes for Hydrogen Production from Coal, Invited Talk at $234^{\text {th }}$ American Chemical Society National Meeting, Boston, MA, Aug. 19-23, 2007.

Dense Membranes for Hydrogen Separation and Purification, "Materials for the Hydrogen Economy," ed. by R. H. Jones and G. J. Thomas, Pg. 147, CRC Press LLC, Boca Raton, FL (2007).

Chemical Stability of Hydrogen Transport Membranes, presented at the $24^{\text {th }}$ Annual International Pittsburgh Coal Conference, Johannesburg, South Africa, Sept. 10-14, 2007.

Development of Dense Membranes for Hydrogen Production and Purification, presented at the American Ceramic Society's Materials Innovations in an Emerging Hydrogen Economy, Cocoa Beach, FL, Feb. 24-26, 2008.

Status of Hydrogen Separation Membrane Development, presented at National Hydrogen Assoc. Annual Hydrogen Conf., Sacramento, CA, March 30 - April 4, 2008.

Development of Dense Membranes for Hydrogen Separation from Coal Gasification Streams, presented at AIChE/ACS Spring Meeting, New Orleans, LA, Apr. 6-10, 2008. 
Development of Membranes for Purifying Hydrogen Produced by Coal Gasification and/or Methane Reforming, presented at the $25^{\text {th }}$ Annual Intl. Pittsburgh Coal Conf., Pittsburgh, PA, Sept. 29-Oct. 2, 2008.

The Effect of Hydrogen Partial Pressure on Uniaxial Creep of 3Y-TZP/50 vol. \% Pd Cermet Membranes, Mat. Sci. Eng. B, 150(3), 145-150 (2008).

Space Charge Potential of Proton-Conducting $\mathrm{BaCe}_{0.8} \mathrm{Y}_{0.2} \mathrm{O}_{2.9-\partial}$, J. Ceram. Process. Res., 9(4), 376-380 (2008).

Thickness Dependence of Hydrogen Permeability in Ni-BaCe ${ }_{0.8} \mathrm{Y}_{0.2} \mathrm{O}_{3-2}$, Solid State Ionics, 179(33-34), 1854-1857 (2008).

Development of Dense Hydrogen Separation Membranes, presented at National Hydrogen Association Annual Hydrogen Conf.,, Columbia, SC, March 30-April 3, 2009.

Development of Cermet Membranes for Hydrogen Separation from Coal Gasification Stream, presented at $26^{\text {th }}$ Annual Pittsburgh Coal Conf., Pittsburgh, PA, Sept. 20-23, 2009.

Stability Study of Dense Ceramic Membranes for Hydrogen Separation, presented at AIChE Conf., San Antonio, TX, March 21-25, 2010.

\section{REFERENCES}

1. U. Balachandran, Hydrogen Separation Membranes-Annual Report for FY 2006, Argonne National Laboratory.

2. U. S. Department of Energy, Hydrogen from Coal Multi-Year RD\&D Plan, September 2009.

3. U. Balachandran, Hydrogen Separation Membranes-Quarterly Report for Oct.-Dec., 2008, Argonne National Laboratory.

4. U. Balachandran, Hydrogen Separation Membranes-Quarterly Report for Jan-Mar., 2009, Argonne National Laboratory.

5. H. Gao, Y. Lin, Y. Li, and B. Zhang, Ind. Eng. Chem. Res., 43, 6920-6930 (2004).

6. S. Hara, K. Sakaki, and N. Itoh, Ind. Eng. Chem. Res., 38, 4913-4918 (1999).

7. H. Amundusson, L.-G. Ekedahl, and H. Dannetun, J. Memb. Sci., 193, 35-47 (2001).

8. U. Balachandran, Hydrogen Separation Membranes--Annual Report for FY 2000, Argonne National Laboratory.

9. S. A. Koffler, J. B. Hudson, and G. S. Ansell, Trans. Met. Soc. AIME, 245, 1735 (1969).

10. S. A. Steward, Review of Hydrogen Isotope Permeability through Membranes, Lawrence Livermore National Laboratory Report, UCRL-53441, 1983.

11. A. Damle, “Commercialization of Pd-Alloy Membrane for $\mathrm{H}_{2}$ Production," presented at National Hydrogen Association Conf. and Expo, Long Beach, CA, May 3-5, 2010.

12. U. Balachandran, Hydrogen Separation Membranes-Annual Report for FY 2009, Argonne National Laboratory. 


\section{Argonne}

\section{Energy Systems Division}

Argonne National Laboratory

9700 South Cass Avenue, Bldg. 212

Argonne, IL 60439-4838

www.anl.gov 